\title{
Current Strategies to Target Tumor-Associated-Macrophages to Improve Anti-Tumor Immune Responses
}

\author{
Clément Anfray ${ }^{1}$, Aldo Ummarino ${ }^{2}(D)$, Fernando Torres Andón ${ }^{1,3}\left(\mathbb{D}\right.$ and Paola Allavena ${ }^{1, *}$ \\ 1 IRCCS Istituto Clinico Humanitas, Via A. Manzoni 56, 20089 Rozzano, Milan, Italy; \\ clement.anfray@humanitasresearch.it (C.A.); fernando.torres.andon@usc.es (F.T.A.) \\ 2 Humanitas University, Via Rita Levi Montalcini 4, 20090 Pieve Emanuele, Milan, Italy; \\ aldo.ummarino@hunimed.eu \\ 3 Center for Research in Molecular Medicine \& Chronic Diseases (CIMUS), Universidade, \\ de Santiago de Compostela, Campus Vida, 15706 Santiago de Compostela, Spain \\ * Correspondence: paola.allavena@humanitasresearch.it
}

Received: 4 December 2019; Accepted: 20 December 2019; Published: 23 December 2019

check for updates

\begin{abstract}
Established evidence demonstrates that tumor-infiltrating myeloid cells promote rather than stop-cancer progression. Tumor-associated macrophages (TAMs) are abundantly present at tumor sites, and here they support cancer proliferation and distant spreading, as well as contribute to an immune-suppressive milieu. Their pro-tumor activities hamper the response of cancer patients to conventional therapies, such as chemotherapy or radiotherapy, and also to immunotherapies based on checkpoint inhibition. Active research frontlines of the last years have investigated novel therapeutic strategies aimed at depleting TAMs and/or at reprogramming their tumor-promoting effects, with the goal of re-establishing a favorable immunological anti-tumor response within the tumor tissue. In recent years, numerous clinical trials have included pharmacological strategies to target TAMs alone or in combination with other therapies. This review summarizes the past and current knowledge available on experimental tumor models and human clinical studies targeting TAMs for cancer treatment.
\end{abstract}

Keywords: tumor-associated macrophages; immune system; tumor microenvironment; immune suppression; cancer immunotherapy; clinical trials

\section{Introduction}

Macrophages are innate immune cells belonging to the mononuclear phagocyte system, which include macrophages resident in peripheral tissues and circulating monocytes newly recruited at sites of inflammation and tissue damage (e.g., tumors). A key feature of macrophages is their phenotypical and functional plasticity, usually defined as polarization, which is dictated by their continuous adaptation and response to specific local stimuli. For instance, macrophages can act as pro-inflammatory and immune-stimulatory effectors in the defense against pathogens, or as anti-inflammatory cells devoted to the healing and remodeling of injured tissues [1-3].

To fulfill such different immune functions, macrophages acquire specific phenotypes that can be characterized in terms of gene expression, the pattern of surface molecules, and the production of biological mediators and metabolites [4-6]. At the edges of the continuum polarization status of macrophages, two extreme phenotypes can be defined as M1 pro-inflammatory/anti-tumor versus M2 anti-inflammatory/pro-tumor. M1-like macrophages, activated by lipopolysaccharides (LPS) and pro-inflammatory cytokines, such as IFN $\gamma$, present the ability to kill tumor cells, inhibit angiogenesis, and promote adaptive immune responses $[3,5]$. However, the uncontrolled activation of inflammatory 
M1 macrophages could represent a risk for the organism. Thus, over time inflammatory macrophages typically shift towards an M2 polarization. At the other extreme, M2-like macrophages, which mimic tumor-associated macrophages (TAMs) present in the tumor microenvironment (TME), can be induced by anti-inflammatory cytokines, such as IL-4 or IL-13. It has been experimentally demonstrated that TAMs or M2-like macrophages promote tumor initiation, progression, and survival; they inhibit immune-stimulatory signals and are devoid of cytotoxic activity [3]. TAM infiltration in tumors has been correlated with poor prognosis [3]. Furthermore, numerous investigations have revealed that TAMs are primarily responsible for resistance to classical anti-tumor treatments (i.e., chemotherapy or radiotherapy), and they also limit the efficacy of new immunotherapies (i.e., anti-PD1) [3,7-9]. These findings called attention to TAMs as promising targets of novel anti-tumor therapeutic approaches.

In this review, we provide an overview of the recent investigations related to TAM interaction with current clinical treatments, which limits their anti-tumor efficacy. In addition, pre-clinical experimentation and clinical trials using TAM-targeted strategies, alone or in combination with chemotherapies, checkpoint blockade immunotherapy, targeted therapy, or radiotherapy, are presented with the aim to provide an overview of the potential of macrophage-targeting approaches for the treatment of cancer.

\section{Origin and Role of Macrophages in Cancer}

In solid tumors, macrophages can represent up to $50 \%$ of the mass, becoming the main immune population. TAMs originate mostly from circulating precursor monocytes, but resident macrophages can be originally present in the tissue, later developing in a tumor $[10,11]$. The origin of monocytes in adults is related to a common myeloid progenitor, which depends on M-CSF (CSF-1) to differentiate into macrophages. Inflammatory monocytes are rapidly recruited at sites of tumor growth, following specific signaling by chemokines (e.g., CCL2), but also CSF-1, cytokines, or complement components (C5a) [3]. Resident macrophages, instead, originate from embryonic precursors that have migrated at peripheral tissues early in life [6].

The origin of TAMs within the tumor (resident macrophages vs. circulating monocytes) is not a mere classification connected to their localization but seems to influence their activity and phenotypic profile [12,13]. Indeed, Franklin and Li showed in murine models of breast cancer that depletion of resident TAMs did not influence tumor growth, while the absence of tumor-recruited TAMs (originating from circulating precursors) resulted in a better outcome [14]. In some tumors, the origin of TAMs is controversial: For example, in brain neoplasia, probably because of the presence of the blood-brain barrier, most (but not all) TAMs derive from resident microglia rather than circulating monocytes [15].

\subsection{Tumor Microenvironment and Its Relation with TAMs}

The relationship between cancer cells, macrophages, and other components of the TME is dynamic and heterogeneous. Considering the evolution of tumors, this immuno-suppressive and pro-angiogenic micro-environment is the physiological result of a process of prolonged inflammation and continuous tissue damage and remodeling. Tumor cells and immune cells in the TME produce cytokines, growth factors, and metabolites, which promote the pro-tumor polarization of TAMs. Biological mediators, such as CSF-1, CCL2, and vascular endothelial growth factor (VEGF), promote the accumulation of TAMs in the TME [4,16-19]. The Th2 cytokines IL-4, IL-13, IL-10, and TGF $\beta$ produced by Treg and TAMs are key drivers of immune-suppression $[5,20]$.

Acidification of the TME caused by lactate derived from enhanced glycolytic activity of cancer cells induces regulatory macrophages through G protein-couple receptor (GPCR) and IL-1 beta-converting enzyme (ICE) [21], enhances VEGF and arginase expression, thus promoting M2-like features of TAMs [22].

The hypoxia-inducible factor $1(\mathrm{HIF}-\alpha)$ is a master transcriptional regulator of cellular response to low oxygen concentration [23-25]. Indeed, the ability of different cells to sense and adapt to oxygen availability has been recognized by the Nobel Prize in Physiology and Medicine in 2019 [26], and this 
also applies to TAMs. Especially in advanced tumors, TAMs accumulate in hypoxic areas; these TAMs are $\mathrm{MHC}^{\text {low }}$, have pro-angiogenic behavior and poor antigen-presenting ability; on the other hand, macrophages localized in areas of normoxia, may be more heterogeneous, and some of them may present an M1 orientation with MHChigh expression [23,27]. Wenes et al. have shown that hypoxic TAMs upregulate REDD1, and endogenous inhibitor of MTORC1, leading to a decrease in glucose intake by TAMs and to higher availability for endothelial cells, thus promoting neo-angiogenesis and metastasis [28].

\subsection{Functions of TAMs in the Tumor Microenvironment}

Although topographical and temporal heterogeneity occurs in tumors, macrophages typically follow a continuum of pro-tumor activation states which can be summarized as follows:

1. Production of growth factors for tumor cells;

2. Promotion of neo-angiogenesis;

3. Release of proteases and other molecules to remodel the extracellular matrix;

4. Secretion of immuno-suppressive mediators (e.g., for T cells), which sabotage the ability of the host immune system to fight cancer.

The epidermal growth factor (EGF) secreted by TAMs promotes the proliferation and invasion of cancer cells, while VEGF regulates angiogenesis. In addition, VEGF receptors on the surface of TAMs signal an autocrine loop, which reinforces their pro-angiogenic and immuno-suppressive functions [3,28,29]. In a similar manner, Tie-2-expressing macrophages bind angiopoietins (Ang-1, Ang-2, etc.) and promote angiogenesis [30]. TAMs also release pro-angiogenic chemokines (e.g., CXCL8) and proteolytic enzymes, such as MMPs and cathepsins, which degrade the extracellular matrix (ECM) inducing the release of angiogenic factors previously stored in the ECM in an inactive form. As an example, it has been demonstrated that MMP-2 and MMP-9 activate TGF $\beta$, VEGF, PDGF, and FGF, and their expression has been correlated to increased tumor invasiveness and worse prognosis $[3,29,31]$. A similar mechanism has been described for the urokinase-like plasminogen activator (uPA), which, upon binding to its receptor (UPAR) on TAMs, induces the cleavage of plasminogen into plasmin, resulting in ECM degradation and consequent release of growth factors and poor outcome [32].

The key driver of metastasis is TGF $\beta$, which can be produced by TAMs; TGF $\beta$ triggers the epithelial-to-mesenchymal transition (EMT), shifting epithelial cancer cells to gain a mesenchymal phenotype, more convenient for motility [33]. The immuno-suppressive function of TAMs is also mediated by the secretion of TGF $\beta$, as well as IL-10, that suppress CD8+ T cell functions by direct transcriptional repression of genes encoding functional mediators, such as perforins, granzymes, and cytotoxins; but also indirectly by stimulating the amplification of Treg cells or by suppressing DC anti-tumor functions $[20,34,35]$. Moreover, TAMs induce amino acid metabolic starvation in T cells through the production of arginase and indoleamine 2,3-dioxygenase (IDO) [25].

In response to hypoxia and to specific cytokines, TAMs overexpress the PD-1 ligands (PD-L1 and PD-L2), as well as the CTLA-4 ligand [36,37]. High PD-L1 expression in TAMs has been reported in different types of cancer, such as hepatocellular carcinoma [38], glioblastoma [39], or pancreatic cancer $[40,41]$. The lack of stimulatory signals from TAMs towards Th1 or CD8+ cytotoxic T cells also contributes to the anergic state of the adaptive immune system in the TME [3]. Finally, TAMs produce some pro-inflammatory cytokines (i.e., IL-6, TNF $\alpha$ ), which contribute to the "smoldering inflammation" present in the TME, which in the long run causes a state of immunosuppression.

Figure 1 synthesizes the pro-tumor and potential anti-tumor functions of TAMs. 


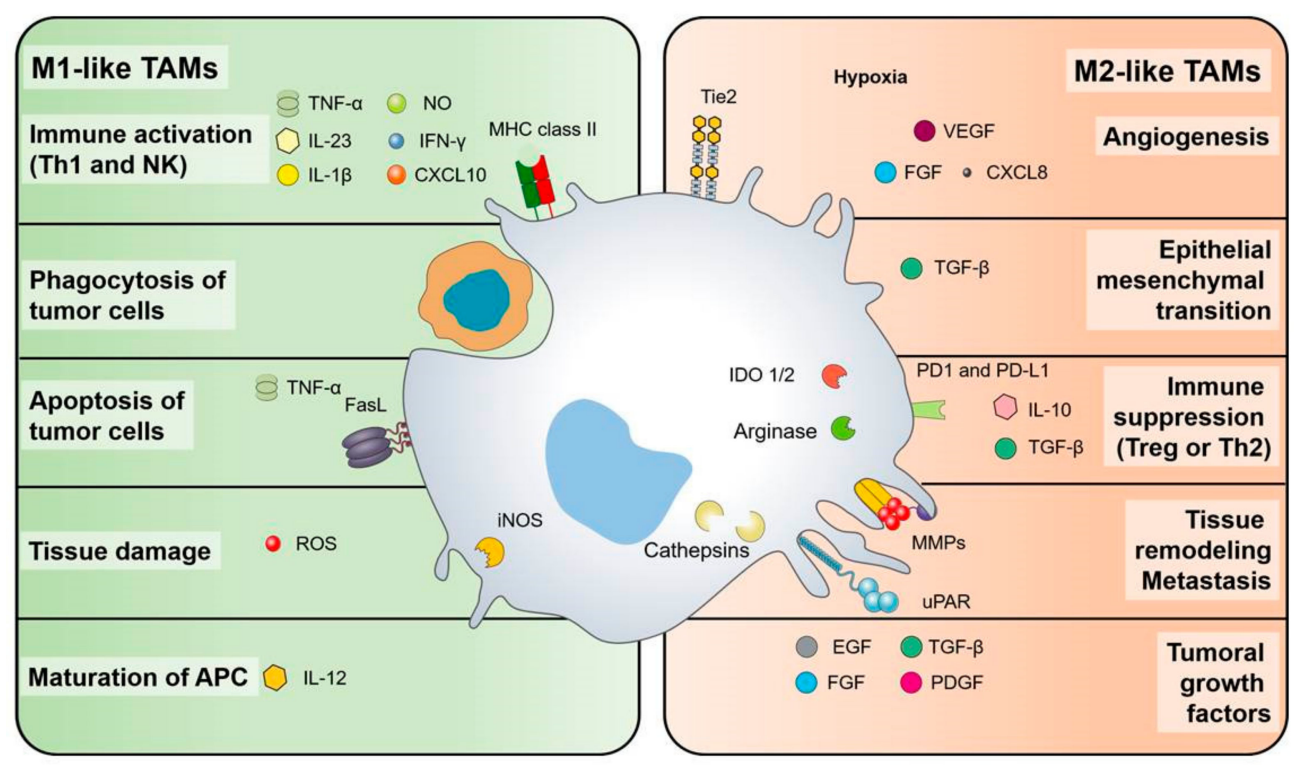

Figure 1. Anti-tumor and pro-tumor functions of tumor-associated macrophages (TAMs). A key feature of macrophages is their intrinsic plasticity, the two extremes of which have been identified as M1-like and M2-like polarization. In the tumor microenvironment, several molecular pathways have been recognized which drive and maintain the phenotypes and functions of TAMs. On the left side, M1-like macrophages, with anti-tumor functions, can be stimulated by immunostimulatory cytokines such as IL-1b, IL-12, IL-23, TNF-alfa, and IFN $\gamma$; MHCII molecules and IL-12 are required for efficient antigen presentation. M1-like TAMs produce chemokines, such as CXCL10, that promotes the recruitment and activation of T cells. In addition, M1-like-TAMs actively phagocytose tumor cells and release TNF-alfa, ROS, and NO for the direct killing of cancer cells. On the right, M2-like macrophages, with pro-tumor functions, are conditioned by the hypoxic tumor micro-environment and by immuno-suppressive mediators (IL-10, TGF $\beta$ ). M2-like-TAMs secrete molecules to promote angiogenesis (CXCL8, VEGF), tumor proliferation (EGF, FGF, PDGF), induce epithelial-mesenchymal-transition (TGF $\beta$ ), and continuous matrix remodeling (MMPs, cathepsins, uPAR). Several immuno-suppressive molecules are produced (IL-10, TGF $\beta$, IDO1/2), which support regulatory T cells.

\section{TAMs Hamper the Efficacy of Current Treatments in Clinical Oncology}

TAMs interfere with most of the anti-tumor therapies commonly used in clinical practice: conventional chemotherapy, anti-angiogenic, radiotherapy, and the novel antibody-based immunotherapies targeting the molecules PD-1/PD-1L and CTLA-4: immune checkpoint blockade (ICB) $[3,8]$.

\subsection{Interaction of TAMs with Immune-Checkpoint Blockade Therapy}

Immune checkpoints are represented by a family of proteins on the surface of $T$ cells, which interact with specific ligands on antigen-presenting cells or cancer cells, and inhibit their TCR-mediated activation. In the last 5 years, anti-checkpoint antibodies have become the holy grail of tumor immunotherapy, resulting in outstanding clinical responses in selected cancer types (i.e., melanoma, lung, and renal cancer). Unfortunately, clinical efficacy is obtained only in a proportion of the treated patients. Moreover, certain cancer types, including pancreatic, colorectal, and ovarian cancer, are refractory to ICB therapy or show little benefit $[9,42]$.

The ability of TAMs to limit the efficacy of ICB therapy has been demonstrated [43,44]. TAMs express ligand molecules for checkpoint receptors, such as PD-L1/2, CD80, CD86 and VISTA (V-domain immunoglobulin suppressor of $\mathrm{T}$ cell activation), and possibly others; the presence of checkpoint inhibitors different from those targeted by the currently available antibodies cancels the benefit of the therapy and maintains a state of strong immunosuppression [40,45-47]. The expression of PD-L1 
by TAMs results in the sequestration of anti-PD-L1 mAbs [45]. Similarly, TAMs can bind anti-PD-1 with their Fc receptor; using intra-vital microscopy, Arlauckas et al. demonstrated that anti-PD-1 co-localizes with $\mathrm{T}$ cells for just a short period $(0.5 \mathrm{~h})$, then the antibody was captured by TAMs for longer time (20 h), de facto hampering the efficacy of the ICB [43].

On the other hand, it is well recognized that macrophages can actively contribute to the clinical efficacy of therapeutic mAbs, such as Rituximab, designed to target B cells by killing the target via a mechanism of antibody-dependent cellular cytotoxicity (ADCC) [48]. This could be of advantage in the case of anti-PD-L1 targeting cancer cells but could be deleterious in the case of anti-PD-1 mAbs killing PD1+ T lymphocytes.

Several investigations have demonstrated that activation of $\mathrm{PI} 3 \mathrm{~K} \gamma$ signaling in macrophages inhibits NF- $\mathrm{KB}$, thereby promoting immune suppression. In several tumor models, the pharmacological inhibition of PI3K $\gamma$ or the stimulation of NF- $\mathrm{kB}$ was able to synergize with ICB therapy to promote tumor regression [49-52]. Other studies showed that high expression by TAMs of the leukemia inhibitory factor (LIF), a member of the IL-6 family, triggers the epigenetic silencing of CXCL9, a chemo-attractant for CD8 + T cells, and LIF inhibition improved the efficacy of anti-PD-1 therapy [53]. Finally, several studies have described how TAMs also interfere with the correct recruitment and localization of CD8+ T cells within the tumor, thus precluding the efficacy of ICB therapy $[54,55]$.

\subsection{Interaction of TAMs with Chemotherapy}

TAMs in tumors treated with chemotherapeutic agents present dual effects: occasionally improving treatment efficacy, but more frequently being primarily responsible for chemoresistance. Among positive effects of TAMs on chemotherapy, early studies by Mantovani pointed out that host defense mechanisms played by macrophages contributed to the therapeutic efficacy of doxorubicin, a concept that has been expanded by Zitvogel's group, as the ability of selected drugs to activate an immunogenic cell death (ICDs) that stimulates anti-tumor immune responses [56,57]. Cancer cells treated with chemotherapy are more susceptible to the cytotoxic effect of macrophages [58], and specific drugs, such as gemcitabine, have been reported to stimulate their cytotoxic potential and M1-like differentiation [59]. On the other hand, TAMs hamper the efficacy of chemotherapeutic drugs by the following mechanisms: (i) increased recruitment of immuno-suppressive myeloid cells, (ii) suppression of adaptive anti-tumor immune responses, (iii) activation of anti-apoptotic programs in cancer cells.

Commonly, chemotherapy-induced tissue damage promotes the recruitment of immuno-suppressive myeloid cells through the secretion of IL-34 and CSF-1 from the cancer cells, in the attempt to heal the injured tissues [60]. In the case of ICD activators, such as doxorubicin, controversial results have been reported, depending on the tumor type and the response of the microenvironment. Breast cancers treated with doxorubicin showed promotion of CCL2 production by stromal cells and consequent recruitment of CCR2+ monocytes, which contributed to tumor relapse [61]. Similarly, in colorectal cancer, 5-fluorouracil (5-FU) increased TAM recruitment in clodronate-depleted tumors [62]. In the same study, Zhang et al. showed that conditioned media from 5-FU-treated macrophages injected in mouse tumors resulted in the inhibition of 5-FU anti-tumor efficacy, being polyamine putrescine, an important component involved in this chemoresistance [62]. In a transgenic mouse model of breast cancer, Salvagno et al. found resistance to platinum-based therapy via the downregulation of type I IFN-stimulated genes (ISGs) in TAMs, which was reverted by CSF-1R blockade therapy and resulted in improved cisplatin efficacy [63]. Platinum-therapy induces the release of fatty acids that act on $\mathrm{F} 4 / 80^{+} / \mathrm{CD} 11^{\text {low }}$ macrophages in the spleen, promoting the release of polyunsaturated lisophosphatidylcholines that alter the DNA damage response and cause resistance to treatment [64]. As TAMs modulate the infiltration and activity of other immune cells through the production of chemokines or metabolites, any modification induced by chemotherapy on macrophages may interfere with the anti-tumor activity. As an example, Ruffel et al. showed that paclitaxel or carboplatin treatment, in mice bearing MMTV-PyMT tumors, is counteracted by the 
increased secretion of IL-10 by TAMs, which downmodulates IL-12 production in DCs and inhibits CD8+ $\mathrm{T}$ cell anti-tumor activity [65].

\subsection{Interaction of TAMs with Anti-Angiogenic Therapy}

TAMs are important mediators of the angiogenic switch in tumors and produce growth factors and other molecules which promote the vessel network, therefore, interfering with anti-angiogenic drugs. In parallel, the pharmacological blocking of angiogenesis, for example, with anti-VEGF mAbs, can cause blood vessel damage, which induces hypoxia and stimulates the secretion of myeloid cell chemoattractants [30]. The comparison of resistant versus sensitive tumors to anti-VEGF therapy revealed a higher number of TAMs in the non-responders [66]. In the same line, anti-VEGF mAbs showed higher therapeutic efficacy and higher inhibition of vessel formation, upon depletion of TAMs with zoledronic acid, in several tumor models [67]. This effect was also observed in murine glioblastoma treated with vatalanib, a small protein kinase inhibitor that blocks angiogenesis. The treatment increased TAM infiltration, and the beneficial effect of the anti-angiogenic therapy was significantly improved with the co-administration of anti-CSF-1R mAb, that impaired TAM recruitment [68]. Finally, the administration of a fully-humanized mAb blocking the Ang2-Tie2 interaction in Tie2-expressing macrophages resulted in the reduction of angiogenesis, but enhanced the recruitment of macrophages, in murine models of breast and pancreatic cancer [30]. TAM reprogramming and depletion of Tie2-expressing macrophages were combined with anti-VEGF therapy for enhanced anti-glioma responses [69].

\subsection{Interaction of TAMs with Radiotherapy}

Radiation therapy (RT) is a widely used and highly cost-effective cancer treatment modality. Interestingly, controversial results have been observed for macrophages in tumors exposed to RT. These could be explained by the former use of conventional RT versus new advanced equipment allowing for precise control of the dose, time, and localization of the RT-treatment, which could be crucial to achieving stimulation or inhibition of immune responses. For example, glioblastoma tumors treated with X-ray radiation showed a general decrease in macrophages and increased M2/M1 ratio of TAMs, and this effect was explained in vitro by the higher resistance of M2 versus M1 macrophages to radiation [70]. Others showed that macrophages irradiated with conventional RT sustain cancer cell invasion and angiogenesis [71], and these observations could be supported by experimental studies demonstrating the improved outcomes of RT in tumor-bearing mice pre-treated with clodronate liposomes to deplete macrophages [72].

On the other hand, several studies have demonstrated that low doses of RT reprogram macrophages towards an iNOS+/M1 phenotype [73,74].

This pro-inflammatory effect can be explained by the ability of RT to "destroy" cancer cells in a similar way to ICD activators, resulting in the release of "danger" signals (DAMPs), such as dsRNA or tumor antigens, which can be recognized by the patient's immune system, triggering effective anti-tumor immune responses [71].

\section{Targeting TAMs: Pre-Clinical Experimentation and Clinical Trials}

As described before, TAMs are involved in many processes that promote tumor growth, including angiogenesis, invasion, metastasis, immunosuppression, and resistance to therapies [3]. The understanding of the molecular mechanisms implicated in these processes and the characterization of TAMs in tumors allowed for the development of original anti-tumor therapeutic strategies, and some of them are currently under evaluation in clinical trials. As a whole, TAM targeting strategies can be divided into two groups: i) strategies designed to inhibit TAM infiltration in tumors, either through inhibition of recruitment or direct killing, and ii) strategies aimed at reprogramming their pro-tumorigenic polarization to activate their anti-tumor functions.

Figure 2 summarizes the available strategies to target TAMs to improve anti-tumor immune responses. 


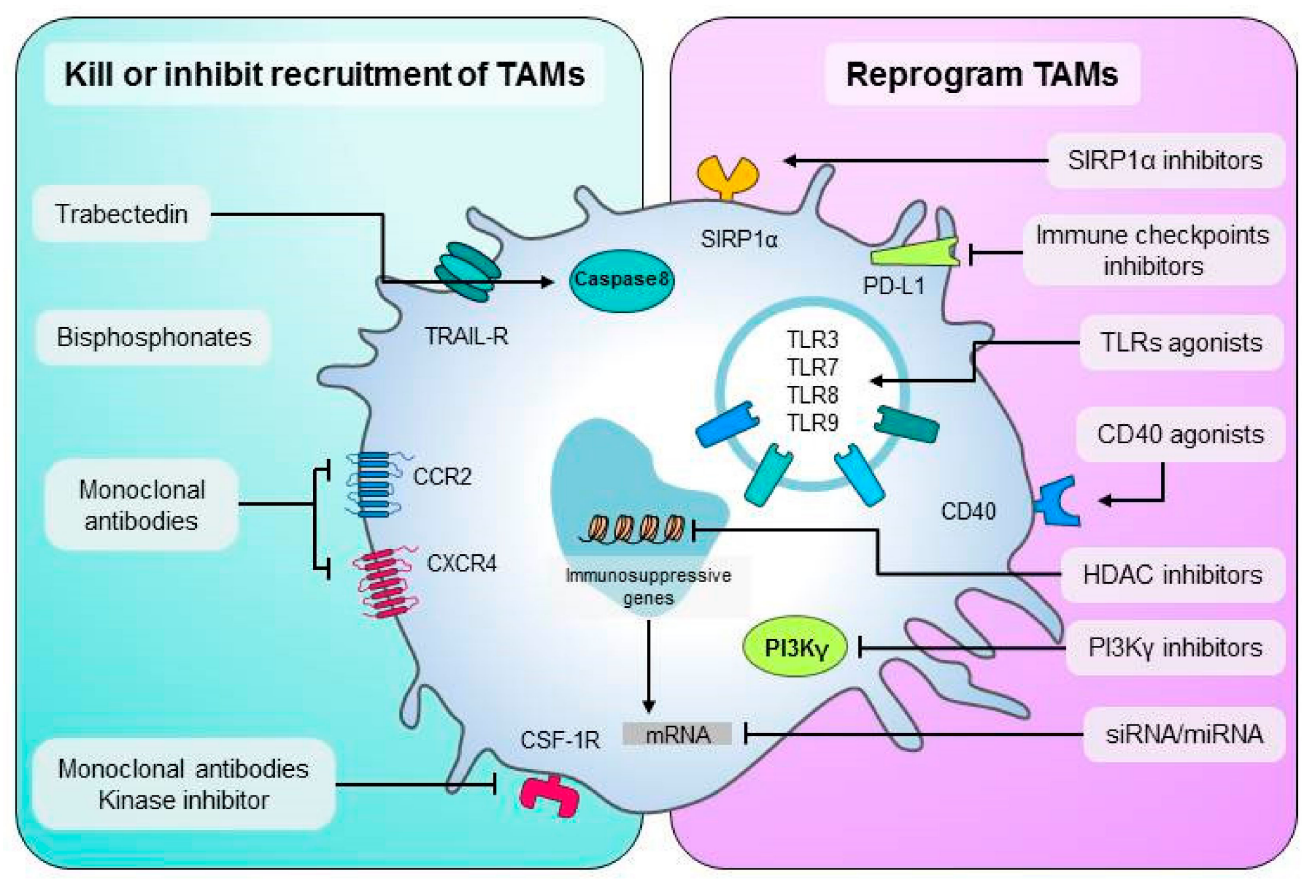

Figure 2. Summary of available therapeutic strategies to target TAMs. On the left side are different approaches to kill macrophages or inhibit their recruitment in tumors. Monoclonal antibodies or kinase inhibitors have been developed to disrupt the CSF-1/CSF-1R, CCL2/CCR2, or the CXCL12/CXCR4 axis required for the recruitment of new macrophages towards the tumor. Traditional bisphosphonates free or loaded into nanocarriers, and also trabectedin are chemotherapeutics, which showed preferential toxicity towards monocytes/macrophages and have been used to reduce their number in tumors. On the right side are strategies to reprogram TAMs into M1-like anti-tumor effectors. Monoclonal agonist antibodies to CD40 or agonists to Toll-like receptors activate TAMs. SIRP1 $\alpha$ inhibitors prevent the block of phagocytosis; mAbs against immune checkpoint ligands, such as PD-L1, can also target TAMs. RNA-based therapies and some small drugs inhibiting histone acetylation (HDAC) or the PI3Kgamma pathway are also under evaluation.

\subsection{Strategies to Inhibit the Recruitment or Number of TAMs in Tumors}

\subsubsection{Strategies to Inhibit TAMs Recruitment}

Strong evidence indicates that the accumulation of macrophages in tumors is due to the continuous recruitment of monocytes from the circulation in response to tumor-derived factors (TDFs). These TDFs are key mediators in the crosstalk between monocytes and tumor cells and include colony-stimulating factor-1 (CSF-1), several C-C chemokine ligands, such as CCL2, also known as MCP-1 and VEGF [75,76]. CCL2 has been described as the major TDF involved in monocyte recruitment, through the CCL2-CCR2 axis. Hence, blockade of CCR2 can suppress the accumulation of TAMs in tumors [75]. CCR2 inhibitors and anti-CCL2 antibodies have shown efficacy in reducing tumor growth and metastasis in several pre-clinical murine models [76]. In addition, anti-CCL2 antibodies were able to improve the efficacy of chemotherapy when administered simultaneously [77]. However, contrasting results were observed in other pre-clinical models. For example, in murine breast cancer, a rebound effect has been noted after the withdrawal of anti-CCL2 treatment, which has been associated with increased mobilization and infiltration of bone-marrow monocytes in the tumor and consequent acceleration of lung metastasis [78]. Clinical trials using anti-CCL2 antibodies have been performed in patients with prostate cancer (Table 1). CCR2 antagonists are being studied as monotherapy in patients with metastatic cancers, or in combination with chemotherapy (FOLFIRINOX) in advanced pancreatic adenocarcinomas, overall with limited results. Anti-CCL2 antibodies were effective in overcoming resistance to radiotherapy in murine models of pancreatic tumors [72]. 
Table 1. Summary of clinical trials to inhibit the recruitment or to deplete TAMs, also in combination with other anti-tumor therapies.

\begin{tabular}{|c|c|c|c|c|}
\hline \multicolumn{5}{|c|}{ CSF-1R Inhibitors (Monotherapy) } \\
\hline \multirow{5}{*}{$\begin{array}{c}\text { PLX3397 } \\
\text { (Pexidarnitib) }\end{array}$} & \multirow{5}{*}{$\begin{array}{c}\text { Melanoma } \\
\text { Advanced solid tumors } \\
\text { PVNS or GCT-TS } \\
\text { Leukemia, sarcoma, or } \\
\text { neurofibroma } \\
\text { Acute myeloid leukemia }\end{array}$} & \multicolumn{2}{|l|}{ Phase II } & NCT02071940 \\
\hline & & \multirow{2}{*}{\multicolumn{2}{|c|}{$\begin{array}{l}\text { Phase I } \\
\text { Phase III }\end{array}$}} & NCT02734433 \\
\hline & & & & NCT02371369 \\
\hline & & \multicolumn{2}{|l|}{ Phase I/II } & NCT02390752 \\
\hline & & \multicolumn{2}{|l|}{ Phase I/II } & NCT01349049 \\
\hline \multirow{2}{*}{ PLX7486 (Plexxikon) } & \multirow{3}{*}{$\begin{array}{l}\text { Advanced-stage or } \\
\text { metastatic solid tumors }\end{array}$} & \multirow{2}{*}{\multicolumn{2}{|c|}{$\begin{array}{l}\text { Phase I } \\
\text { Phase I }\end{array}$}} & NCT01804530 \\
\hline & & & & NCT03069469 \\
\hline $\begin{array}{l}\text { DCC-3014 } \\
\text { ARRY-382 }\end{array}$ & & \multicolumn{2}{|l|}{ Phase I } & NCT01316822 \\
\hline \multirow{2}{*}{ LY3022855 mAb (IMC-CS4) } & \multirow{2}{*}{ Solid tumors } & \multirow{2}{*}{\multicolumn{2}{|c|}{$\begin{array}{l}\text { Phase I } \\
\text { Phase I }\end{array}$}} & NCT02265536 \\
\hline & & & & NCT01346358 \\
\hline AMG820 mAb & Solid tumors & \multicolumn{2}{|l|}{ Phase I } & NCT01444404 \\
\hline \multicolumn{5}{|c|}{ CCR2 Inhibitors (Monotherapy) } \\
\hline CNTO 888 (Carlumab) & Prostate cancer & Phase II & & NCT00992186 \\
\hline PF-04136309 & Pancreatic cancer & Phase I/II & & NCT02732938 \\
\hline MLN1202 & Bone metastasis & Phase I/II & & NCT01015560 \\
\hline \multicolumn{5}{|c|}{ CSF-1R Inhibitors + Checkpoint Immunotherapy } \\
\hline \multirow{2}{*}{ PLX3397 (Pexidarnitib) } & Pembrolizumab & Solid tumors & Phase I/II & NCT02452424 \\
\hline & Durvalumab & Advanced tumors & Phase I & NCT02777710 \\
\hline \multirow{2}{*}{ LY3022855 mAb (IMC-CS4) } & $\begin{array}{l}\text { Pembrolizumab } \\
\text { Durvalumab }\end{array}$ & Pancreatic cancer & Phase I & NCT03153410 \\
\hline & Tremelimumab & Advanced solid tumors & Phase I & NCT02718911 \\
\hline $\begin{array}{l}\text { RO5509554/RG7155 } \\
\text { (Emactuzumab) }\end{array}$ & Atezolizumab & Solid tumors & Phase I & NCT02323191 \\
\hline AMG820 mAb & Pembrolizumab & Solid tumors & Phase I/II & NCT02713529 \\
\hline BLZ945 & PRD001 & Advanced solid tumors & Phase I/II & NCT02829723 \\
\hline Cabiralizumab & Nivolumab & Advanced solid tumors & Phase I & NCT02526017 \\
\hline \multicolumn{5}{|c|}{ CCR2 Inhibitors + Checkpoint Immunotherapy } \\
\hline $\begin{array}{c}\text { BMS-813160 (CCR2/CCR5 } \\
\text { antagonist) }\end{array}$ & Nivolumab & Advanced solid tumors & Phase I/II & NCT03184870 \\
\hline \multicolumn{5}{|c|}{ CSF-1R Inhibitors + Chemotherapy } \\
\hline PLX3397 (Pexidarnitib) & $\begin{array}{c}\text { Paclitaxel } \\
\text { Standard Chemotherapy }\end{array}$ & Advanced solid tumors & Phase I/II & $\begin{array}{l}\text { NCT01525602 } \\
\text { NCT01042379 }\end{array}$ \\
\hline $\begin{array}{l}\text { RO5509554/RG7155 } \\
\text { (Emactuzumab) }\end{array}$ & Paclitaxel & Advanced solid tumors & Phase I & NCT01494688 \\
\hline PD-0360324 mAb & Cyclophosphamide & Ovarian cancer & Phase II & NCT02948101 \\
\hline \multicolumn{5}{|c|}{ CCR2 Inhibitors + Chemotherapy } \\
\hline CNTO 888 (Carlumab) & $\begin{array}{l}\text { Gemcitabine/paclitaxel } \\
\text { Carboplatin/doxorubicin }\end{array}$ & Advanced solid tumors & Phase II & NCT01204996 \\
\hline PF-04136309 & FOLFIRINOX & Advanced solid tumors & Phase I/II & NCT01413022 \\
\hline \multicolumn{5}{|c|}{ CSF-1R Inhibitors + Targeted Therapy } \\
\hline PLX3397 (Pexidarnitib) & $\begin{array}{l}\text { Sirolimus (Rapamycin) } \\
\text { Eribulin }\end{array}$ & $\begin{array}{c}\text { Sarcoma } \\
\text { Metastatic breast cancer }\end{array}$ & Phase I/II & $\begin{array}{l}\text { NCT02584647 } \\
\text { NCT01596751 }\end{array}$ \\
\hline \multicolumn{5}{|c|}{ CSF-1R Inhibitors + Radiotherapy } \\
\hline PLX3397 (Pexidarnitib) & $\mathrm{RT}+\mathrm{ADT}$ & Prostate cancer & $\begin{array}{c}\text { Phase I } \\
\text { Phase I/II }\end{array}$ & NCT02472275 \\
\hline & RT + Temozolomide & Glioblastoma & Phase I/II & NCT01/90503 \\
\hline
\end{tabular}

Another combination therapy, investigated in ongoing Phase $\mathrm{Ib} / \mathrm{II}$ clinical trials, consists in the use of a dual CCR2/CCR5 antagonist plus chemotherapy or nivolumab in patients with metastatic 
colorectal and pancreatic cancer. CCR5 has been related to the recruitment of polymorphonuclear MDSCs (PMN-MDSCs) and T cells in the TME. Thus, it will be of interest to evaluate the balance efficacy/safety of CCR2- or CCR5-selective inhibition versus dual inhibition in combination with chemotherapy or anti-PD-1 therapy (Table 1).

Another axis involved in monocyte recruitment and differentiation into TAMs is the CXCL12/CXCR4 axis $[79,80]$. In a breast cancer model, expression of CXCL12 by tumor cells increased macrophage and vessel density, contributing to the invasion ability of tumor cells. Inhibition of CXCR4 with the antagonist AMD3100 reduced tumor cell spreading and formation of metastasis [81]. AMD3100 is under evaluation in combination with pembrolizumab, in a recently initiated clinical trial for patients with refractory head and neck squamous cell carcinoma (NCT04058145). Previously, a couple of clinical trials investigated the safety of continuous intravenous administration of another CXCR4 antagonist (plerixafor) and its impact on the tumor microenvironment (NCT02179970, NCT03277209) in patients with solid tumors. Plerixaflor is also under evaluation in patients with acute myeloid leukemia (AML) in combination with G-CSF, which downregulates CXCL12 expression and acts synergistically in stem cell mobilization (NCT00906945), or in combination with several chemotherapeutics to treat relapsed or refractory AML (NCT01236144, NCT01220375, NCT01027923). Similar studies are being performed with other CXCR4 antagonists (NCT01010880, NCT02907099, NCT02115672, NCT02954653, NCT02737072, NCT01359657, NCT01120457).

The inhibition of CXCL12 reduced the myeloma-supportive activity of the bone marrow microenvironment and mobilized myeloma cells into the circulation. Olaptesed pegol (NOX-A12) is a pegylated L-oligoribonucleotide that binds and neutralizes CXCL12, achieving the mobilization of myeloma cells for at least $72 \mathrm{~h}$ and enhancing the activity of dexamethasone without relevant additional toxicity [82] (NCT04121455). This approach is also being investigated in combination with pembrolizumab in patients with colorectal and pancreatic cancer (NCT03168139).

\subsubsection{Strategies to Deplete TAMs}

The growth factor CSF-1 is involved in the proliferation, differentiation, and survival of monocytes/macrophages that originated from bone marrow progenitor cells. A high level of CSF-1 or CSF-1R expression in the tumor or peri-tumor tissue has been associated with poor patient survival in lymphoma, breast cancer, and hepatocellular carcinoma [83-86]. Strong evidence supports the CSF-1/CSF-1R axis as an attractive target to reduce the number of TAMs in tumors. Consequently, the pharmacological inhibition of the CSF-1/CSF-1R axis alone or in combination with different therapies has been explored in pre-clinical settings and in clinical trials, preferentially in patients with advanced solid tumors. Antibodies and small molecules have been developed to target the CSF-1 receptor or its downstream signaling pathways (Table 1). In animal models, emactuzumab, a humanized mAb targeting CSF-1R, resulted in decreased TAM numbers in the tumor and increased CD8+/CD4+ T cell ratio [87]. The evaluation of this $\mathrm{mAb}$ alone or in combination with paclitaxel in patients with advanced solid tumors revealed an important reduction of TAMs in the TME and a good safety profile, but so far, no clinically relevant improved outcomes [88,89]. Similar mAbs targeting CSF-1R are currently being investigated in clinical trials as monotherapy or in combination with ICB for advanced solid tumors and with cyclophosphamide in patients with ovarian cancer (Table 1).

Macrophage depletion by CSF-1R blockade with small molecule inhibitors also showed increased infiltration of CD8+ cytotoxic $\mathrm{T}$ cells in the tumor and improved response to therapies in murine models of breast, prostate, and cervical tumors [60,90,91]. TAMs can trap CD8+ T cells at the tumor periphery, thus having a detrimental impact on $\mathrm{T}$ cell motility inside the tumor. The inhibition of CSF-1R using the small drug PLX3397 was effective to deplete TAMs and to restore T cell migration into the TME of mouse mammary tumor models [55]. In pancreatic cancer, not responding to ICB therapy, a combination of anti-PD1 or anti-CTLA-4 checkpoint immunotherapy with PLX3397 improved anti-tumor immunity and led to the regression of established primary pancreatic tumors [92]. PLX3397 has also been combined with the TORC1 inhibitor rapamycin for the treatment of malignant peripheral 
nerve sheath tumors. This highly aggressive tumor, resistant to chemotherapy and to imatinib, showed a significant depletion of macrophages and tumor reduction after PLX3397 treatment, which was improved by its combination with rapamycin, even when drug treatment was discontinued [93].

Inhibition of the CSF-1/CSF-1R axis is presently explored in Phase I/II clinical trials in patients (Table 1). The combination PLX3397 plus eribulin, a macrocyclic ketone analog that inhibits microtubule dynamics, is being tested in patients with metastatic breast cancer and soft tissue sarcoma. PLX3397 also improved the efficacy of the BRAF inhibitor veramufenib in murine models of melanoma, and this therapeutic combination is ongoing in patients with $\mathrm{BRAF}^{\mathrm{V} 600}$ mutant metastatic melanoma [94]. Other recent studies suggested that inhibition of the CSF-1/CSF-1R axis is a promising strategy to treat primary and metastatic KRAS-tumors resistant to immune checkpoint blockade. As an example, CSF-1/CSF-1R blockade decreased fibrosis of primary and metastatic tumors in KRAS pancreatic mouse models, resulting in increased CD8+ T cell infiltration [41,95]. Other studies have reported on the ability of CSF-1R inhibition alone or in combination with other therapies to induce TAM reprogramming towards an anti-tumor M1 phenotype [96] (see Section 4.2.4).

Radiotherapy has been combined with several TAM-targeted therapies. Of note, instead of depleting TAMs, the inhibition of CSF-1 after ionizing radiation resulted in altered myeloid cell recruitment and polarization. PLX3397 plus radiotherapy increased CSF-1 expression and myeloid cell infiltration in preclinical mouse xenograft models of human glioblastomas [97]. Clinical trials are currently studying the combination of PLX3397 and radiotherapy with temozolomide for glioblastoma, or androgen deprivation therapy for prostate cancer (Table 1). Combinations of anti-CCL2 antibodies with radiotherapy are also being tested in pre-clinical and clinical studies [72,98].

Previous to the discovery of compounds targeting the CSF-1/CSF-1R axis, other drugs with preferential cytotoxic activity towards monocytes/macrophages have been used. For example, bisphosphonates, which are typically used for the treatment of osteoporosis and for the prevention of complications associated with bone metastases. Following administration, these inorganic compounds are selectively adsorbed into the bone tissue and metabolized by osteoclasts, thus limiting systemic exposure [29]. In addition to osteoclasts, tissue macrophages, including TAMs, have been reported to be affected by bisphosphonates, alone or in combination with chemotherapy. Several nanoparticles (NPs) have been used to improve the delivery of bisphosphonates to TAMs, the most popular being liposomal formulations of clodronate, which showed anti-tumor efficacy in several murine models of colon cancer, glioma, and myeloma [3,29]. Clodronate liposomes are commonly used in biomedical research to deplete macrophages to understand their function in vivo. However, the high toxicity of this approach limits the translational relevance of these studies $[99,100]$.

Trabectedin is a registered anti-neoplastic drug, which in addition to targeting tumor cells, can partially deplete circulating monocytes and TAMs through a TRAIL-dependent pathway of apoptosis [101]. Our group showed that unlike neutrophils and lymphocytes (that express the decoy TRAIL receptors: TRAILR3), monocytes and macrophages express the functional TRAIL receptors 1 and 2: TRAILR1 and TRAILR2, and are, therefore, susceptible to the cytotoxic effect of trabectedin [101].

A preclinical study recently showed in a chronic lymphocytic leukemia mouse model that trabectedin induced leukemic cell death and depletion of the immuno-suppressive myeloid-derived suppressor cells and TAMs [102]. Anti-tumor activity by trabectedin, through effects on TAMs, has also been reported in pre-clinical models of skeletal metastatic prostate tumor, melanoma, and pancreatic tumor [103-105].

As macrophages play a crucial role in host defense, homeostasis, and erythropoiesis, non-specific depletion of TAMs may be harmful [106]. The scavenging receptor CD163, a marker of M2 macrophages and TAMs, has been shown to promote their pro-tumor activities in mice and humans $[107,108]$.

Using CD163 mAbs conjugated with lipid NPs loaded with doxorubicin (DOX), Etzerodt et al. showed in a mouse melanoma model that selective depletion of CD163+ macrophages re-educates the TME through increased recruitment of $\mathrm{T}$ cells and monocytes, which both contribute to tumor regression. Interestingly, in this model, the pan-targeting of TAMs abrogated the therapeutic effects 
observed with the specific targeting of CD163+ TAMs [109]. The overall lack of efficacy observed with therapeutic approaches currently in clinical trials, such as CSF1/CSF1R or CCL2/CCR2 blockade, that indiscriminately target all macrophages, may be in part explained by these findings. A better understanding of the specific TAM subset, which mostly contributes to tumor progression, is needed.

Long-lasting macrophage depletion may also have detrimental effects. A few studies reported that prolonged CSF-1R inhibition leads to an acquired resistance and tumor recurrence through activation of the PI3K pathway; the combination of PI3K blockade with CSF-1R inhibition prolonged survival in pre-clinical models [110]. Compensatory effects and enhanced tumor progression in response to CSF-1R inhibition has been recently attributed to increased granulocyte recruitment into tumors. Speicher et al. reported that CSF-1R inhibition combined with CXCR2 antagonists blocks granulocyte infiltration and results in stronger anti-tumor effects [111].

Overall, lack of selectivity towards the specific myeloid subsets with pro-tumor activity, and problems associated with the unwanted depletion of macrophages in other organs for a prolonged period, has limited the clinical translation of these depleting strategies. Even more, recent studies indicate that reprogramming of macrophages—rather than TAM depletion-might be more beneficial in eliciting an effective anti-tumor immune response.

\subsection{Strategies to Reprogram TAMs}

Myeloid functional plasticity, as mentioned above, opens possibilities for the pharmacological reprogramming of macrophages in the light of therapeutic exploitation. Several approaches have been attempted with the aim to switch M2-like macrophages with pro-tumor properties into anti-tumor M1-like macrophages. These include the use of Toll-like receptor agonists, nucleic acids (i.e., miRNA or siRNA), and monoclonal antibodies.

\subsubsection{Targeting the Toll-Like Receptors for TAM Reprogramming}

Toll-like receptors (TLRs) are innate immunity pattern recognition receptors that, upon engagement by their ligands, stimulate macrophages and activate an M1-like functional polarization [3]. For this reason, the capacity of different TLRs agonists to reprogram TAMs into anti-tumor effectors has been evaluated. In the last years, the pharmacological targeting of TLR3, TLR7, TRL8, and TLR9 located in the endosomal compartment of antigen-presenting cells, such as macrophages, has been prioritized versus extracellular TLRs, presumably due to their higher capacity to trigger anti-tumor immune responses. Currently, only imiquimod (TLR7 agonist) is FDA approved for topical administration in squamous and basal cell carcinoma.

We have recently shown that stimulation of tumor-conditioned macrophages with poly I:C (TLR3 agonist) is superior to imiquimod (R837) for their reprogramming into cytotoxic effectors [112]. Indeed, a crucial role for TLR3 stimulation to revert M2-macrophages polarization towards M1 has also been reported by others $[113,114]$. In a recent study, ROS-inducing polypeptide micelles were loaded with poly I:C and grafted with galactose groups to enable their specific uptake by TAMs in vitro and in vivo. These NPs were recognized by the galactose-specific C-type lectin (MGL) receptor expressed on the TAM surface and induced their re-education towards M1-like macrophages, activating NK and effector T cells, and ultimately leading to tumor regression in a murine melanoma model [115]. Zhao et al. reported a synergistic effect of poly I:C with Ferumoxytol ${ }^{\circledR}$, an FDA-approved NP for the treatment of iron deficiency, to promote TAM polarization [116]. Combined into a unique NP, in vitro, it upregulated TNF- $\alpha$ and iNOS expression, increased NO secretion, and phagocytosis. In vivo, this treatment induced macrophage activation accompanied by primary and metastatic regression in a murine model of melanoma [117].

Poly I:C is being evaluated in clinical trials upon i.m. injection in combination with i.v. infusion of anti-PD-1 therapy in patients with hepatocellular carcinoma, while its analog, poly-ICLC, has been evaluated as a cancer vaccine to boost anti-tumor responses. A phase II clinical trial is investigating the sequential intra-tumor plus i.m. administration of poly-ICLC alone or in combination with ICB therapy 
in melanoma, head and neck and sarcoma cancers. Similarly, the TLR9 agonist CpG is currently being evaluated in clinical trials for lymphomas in combination with Ibrutinib or radiation therapy, and for the treatment of HCC in combination with the anti-OX40 mAb (BMS-986178).

Resiquimod (R848), an agonist to TLR7/8, has attracted much attention in the past few years for its capacity to reprogram macrophages. R848 is an imidazoquinoline, analog to Imiquimod, but presumably more powerful as TLR agonist, with the ability to trigger stronger anti-tumor responses [118-120]. Although, to our knowledge, resiquimod is not being investigated in clinical trials, several studies have been performed in melanoma patients with topical administration or local injection, mainly in combination with vaccine therapy. Despite some promising results, the systemic administration of imidazoquinolines is burdened with toxicity: whole-body inflammation, hematologic toxicity (lymphopenia, anemia), and flu-like symptoms [121,122]. To solve this problem, R848 has been covalently linked to vitamin $\mathrm{E}$ and modified with hyaluronic acid, thus becoming a pro-drug nanoformulation. The subcutaneous injection of this nanotherapeutic formed a depot that provided a sustained release of $\mathrm{R} 848$.

Another formulation of R848, MEDI9197 (3M-052), was designed to be retained at the injection site, thus limiting systemic toxicity [123]. As an alternative, to allow the intravenous administration and, at the same time, to limit its systemic toxicity, Rodell et al. developed $\beta$-cyclodextrin-NPs, loaded with R848 to target TAMs in vivo. This strategy was able to induce the production of the pro-inflammatory cytokine IL-12 by TAMs in the TME. Furthermore, the combination of these NPs with anti-PD-1 antibodies re-established their anti-tumor response in a murine cancer model resistant to ICB therapy [124].

Lately, some researchers have studied the effect of combinatorial stimulation of TLRs to achieve a synergistic activation of macrophages. In 2016, Liu et al. measured cytokine secretion by macrophages exposed to poly I:C and R848, and they found that activation of the JAK-STAT pathway through TLR3 stimulation is desirable to prime macrophages for subsequent synergistic response to TLR7 [125].

Despite these promising results in vitro, the information related to the in vivo application of combinations of TLRs for the treatment of cancer is still very limited, with only a few pieces of evidence in the field of cancer vaccination for their application as adjuvants. In this regard, NPs loaded with poly I:C and R837 [126] or R848 for vaccination purposes [127], showed the ability to trigger a strong innate immune response in lymph nodes, resulting in therapeutic efficacy without the systemic release of pro-inflammatory cytokines. Poly-ICLC plus R848 have been investigated in the clinic in combination with a cancer vaccine in patients with advanced tumors expressing the NY-ESO-1 protein. Finally, TLR agonists have also been combined with immunogenic cell death (ICD) activators, such as oxaliplatin or doxorubicin $[128,129]$. While the TLR agonists activate innate immunity cells, ICDs trigger the release of tumor antigens: Thus, the combined treatment should result in TAM reprogramming and strong antigen-specific $\mathrm{T}$ cell responses against tumors.

\subsubsection{RNA Delivery to Reprogram TAMs}

With technological advances made in oligonucleotide delivery, mRNA, siRNA, or miRNA therapies are now promising strategies to manipulate macrophages for the treatment of cancer. As an example to deliver mRNA into TAMs, charge-altering releasable transporters (CARTs) have been developed, using oligo (carbonate-b-alfa-amino ester)s, as dynamic carriers. These have the ability to complex, protect, and deliver polyanionic mRNA through a controlled degradation and facilitate the cytosolic release of functional mRNA [130]. This method has been used to deliver a combination of OX40L, CD80, and CD86 encoding mRNAs in different subcutaneous two-tumor models, where only one tumor was treated. Upon intra-/peri-tumor administration, CARTs successfully transfected tumor-infiltrating cells, including $28 \%$ of TAMs, cured the treated tumor, and induced a systemic anti-tumor immunity, as seen by the regression of the second untreated tumor [131].

In another study, Zhang et al. administered biodegradable polymeric NPs encapsulating two mRNAs and functionalized with di-mannose moieties on their surface to target and re-educate TAMs. 
A first mRNA encoding IRF5, a member of the interferon regulatory factor family, and a second one encoding IKK $\beta$, a kinase that phosphorylates and activates IRF5, were able to downregulate the expression of M2 genes, such as Serpinb2 and CCL11, and to upregulate the M1 gene CCL5. In a murine ovarian tumor model, i.p. injections effectively reprogrammed TAMs towards M1-like macrophages and increased $\mathrm{T}$ cell and neutrophil infiltration into the tumors. Ex vivo treated-TAMs expressed increased levels of cytokines IL-12, IFN- $\gamma$, and TNF- $\alpha$, while IL- 6 was decreased. The same treatment was also effective in a murine model of glioma and lung metastasis [132].

Small interfering RNA (siRNA) has been used to silence the expression of genes that regulate the immuno-suppressive functions of TAMs [133,134]. Song et al. designed mannosylated dual pH-responsive NPs loaded with 2 siRNAs directed against VEGF and placental growth factor (PIGF). These two growth factors, overexpressed in breast cancer cells and TAMs, promote tumor proliferation and immunosuppression. In a murine breast cancer model, these NPs efficiently delivered the siRNAs to both TAMs and cancer cells, resulting in gene silencing and inhibition of tumor growth and lung metastasis [135].

MicroRNA (miRNA) are small non-coding RNA molecules that function in RNA silencing and post-transcriptional regulation of gene expression. Cai et al. developed lipid-coated calcium phosphonate NPs containing conjugated mannose to facilitate the delivery of miRNA-155 to reprogram TAMs towards an M1 phenotype [136]. These NPs were shielded with a $\mathrm{pH}$-responsive material preventing particle uptake at physiological $\mathrm{pH}$ and enabling mannose exposure and uptake by TAMs in the acidic tumor microenvironment. In a mouse sarcoma model, this delivery system reduced TAM expression of IL-10, MMP9, and VEGF, and increased expression of IL-12. This effect was associated with decreased tumor growth and prolonged survival [137].

To our knowledge, no clinical trials have been initiated using RNA delivery technology to reprogram macrophages. Old clinical trials have used several approaches to transfect mRNA for dendritic cell reprogramming; some trials are currently investigating the use of "personalized" mRNA tumor vaccines encoding neo-antigens in combination with ICB therapy, mainly for melanoma, lymphoma, head and neck and breast cancer. Another Phase I/II multicenter study is using liposomes loaded with mRNA-2416, which encodes human OX40L, in combination with anti-PD-L1 therapy in patients with advanced tumors.

\subsubsection{Antibodies to Reprogram TAMs}

The CD47-SIRP $\alpha$ axis is involved in the regulation of phagocytosis. CD47 is expressed by tumor cells and interacts with the signal regulatory protein- $\alpha$ (SIRP $\alpha$, also known as SHPS1) expressed on the surface of phagocytic cells, such as macrophages and dendritic cells. This interaction results in the inhibition of phagocytosis and thus acts as a "don't eat me" signal, important for tissue homeostasis. Substantial evidence has been provided that overexpression of CD47 by many cancer types is an important mechanism of resistance to phagocytosis [138]. The pharmacological inhibition of CD47 restored phagocytosis and killing of tumor cells by macrophages in various preclinical cancer models, resulting in effective anti-tumor immune responses [139-141]. Combination therapies have the potential to increase this efficacy. As an example, the reprogramming of TAMs towards an M1 phenotype has been achieved by the combination of SIRP $\alpha$-blocking antibodies with CSF-1R inhibitors assembled into a unique supramolecular-system. Repolarization of TAMs was associated with increased phagocytosis of cancer cells and enhanced anti-tumor efficacy [142,143].

Promising results were obtained in patients with aggressive or indolent lymphoma with a combination of anti-CD47 mAbs and anti-CD20 (Rituximab ${ }^{\circledR}$ ) to target B cells [144]. Based on this evidence, several clinical trials are now being performed with anti-CD47 mAbs or CD47-Fc fusion proteins for the treatment of different tumor types, also in combination with anti-PD-1 therapy (Table 2). 
Table 2. Summary of clinical trials to reprogram TAMs, also in combination with other anti-tumor therapies.

\begin{tabular}{|c|c|c|c|c|}
\hline \multicolumn{5}{|c|}{ CD47 Inhibitors (Monotherapy) } \\
\hline Hu5F9-G4 mAb & \multicolumn{2}{|c|}{$\begin{array}{c}\text { Myeloid leukemia } \\
\text { Acute myeloid leukemia }\end{array}$} & Phase I & NCT02678338 \\
\hline \multirow{2}{*}{ CC-90002 mAb } & \multirow{2}{*}{\multicolumn{2}{|c|}{$\begin{array}{c}\text { Myeloid leukemia } \\
\text { Advanced solid or hematologic cancers }\end{array}$}} & Phase I & NCT02641002 \\
\hline & & & Phase I & NCT02367196 \\
\hline SRF231 mAb & \multicolumn{2}{|c|}{ Advanced solid or hematologic cancers } & Phase I & NCT03512340 \\
\hline $\begin{array}{c}\text { TTI-621 } \\
\text { (CD47-Fc fusion protein) }\end{array}$ & \multicolumn{2}{|c|}{ Hematologic malignancies } & Phase I & NCT02663518 \\
\hline \multicolumn{5}{|c|}{ CD40 mAb Agonists (Monotherapy) } \\
\hline $\mathrm{CP}-870,893$ & & Melanoma & Phase I & NCT02225002 \\
\hline \multicolumn{5}{|c|}{ CD47 Inhibitors + Checkpoint Immunotherapy } \\
\hline $\begin{array}{c}\text { TTI-621 } \\
\text { (CD47-Fc fusion protein) }\end{array}$ & $\begin{array}{l}\text { PD-1/PD-L1 } \\
\text { inhibitors }\end{array}$ & $\begin{array}{l}\text { Relapsed and refractory } \\
\text { solid tumors }\end{array}$ & Phase I & NCT02890368 \\
\hline $\begin{array}{c}\text { TTI-622 } \\
\text { (CD47-Fc fusion protein) }\end{array}$ & PD-1 inhibitors & $\begin{array}{l}\text { Relapsed and refractory } \\
\text { lymphoma or myeloma }\end{array}$ & Phase I & NCT03530683 \\
\hline \multicolumn{5}{|c|}{ CD40 mAb Agonists + Checkpoint Immunotherapy } \\
\hline APX005M & Nivolumab & Advanced solid tumors & Phase I & NCT03502330 \\
\hline $\begin{array}{l}\text { RO7009789 } \\
\text { (Selicrelumab) }\end{array}$ & Atezolizumab & $\begin{array}{l}\text { Advanced or metastatic } \\
\text { solid tumors }\end{array}$ & Phase I & NCT02304393 \\
\hline \multicolumn{5}{|c|}{ CD47 Inhibitors + Targeted Therapy } \\
\hline Hu5F9-G4 mAb & $\begin{array}{c}\text { Rituximab } \\
\text { (anti-CD20 mAb) }\end{array}$ & $\begin{array}{l}\text { Relapsed and refractory } \\
\text { lymphoma }\end{array}$ & Phase I/II & NCT02953509 \\
\hline \multicolumn{5}{|c|}{ CD40 mAb Agonists + Targeted Therapy } \\
\hline \multirow{2}{*}{$\begin{array}{c}\text { RO7009789 } \\
\text { (Selicrelumab) }\end{array}$} & $\begin{array}{c}\text { Vanucizumab } \\
\text { (anti-ANG-2-VEGF } \\
\text { bispecific } \mathrm{Ab} \text { ) }\end{array}$ & Solid tumors & Phase I & NCT02665416 \\
\hline & $\begin{array}{l}\text { Emactuzumab } \\
\text { (anti-CSF-1R Ab) }\end{array}$ & Advanced solid tumors & Phase I & NCT02760797 \\
\hline
\end{tabular}

Antigen-presenting cells, such as macrophages and dendritic cells, express on their surface CD40, a receptor of the TNF receptor superfamily. Interaction with its ligand CD40L, mainly expressed by $\mathrm{T}$ cells, basophils, and mast cells, upregulates the expression of MHC molecules and secretion of pro-inflammatory cytokines, promoting $\mathrm{T}$ cell activation [145]. In various murine tumor models, agonistic anti-CD40 antibodies have led to the recovery of tumor immune surveillance, mediated by the reprogramming of TAMs towards M1-polarization and effective anti-tumor activity [146-148]. The combination of anti-CD40 plus anti-CSF-1R antibodies has been evaluated in "cold" preclinical tumor models, not responsive to ICB. This combination therapy was able to turn "cold" into "hot" tumors with an overall decrease in immuno-suppressive cells, enhanced activity of infiltrating $\mathrm{T}$ cells and potent anti-tumor immunity [149]. Anti-CD40 mAbs are under evaluation in combination with checkpoint immunotherapy, chemotherapy, or targeted therapies in patients with advanced solid tumors (Table 2).

\subsubsection{Other Strategies to Reprogram TAMs}

In 2016, Kaneda et al. investigated the role of PI3K $\gamma$ in the immuno-suppressive activity of TAMs. They showed that $\mathrm{PI} 3 \mathrm{~K} \gamma$ controls the switch between immune stimulation to suppression through the inhibition of the NF- $\mathrm{kB}$ pathway and activation of C/EBP $\beta$. Selective inhibition of PI3K $\gamma$ reverted 
this effect and resulted in pro-inflammatory cytokine expression, CD8+ T cell recruitment to tumors, and tumor growth inhibition [49]. In a preclinical model of pancreatic cancer, it has been shown that interactions between B cells and $\mathrm{FcR} \gamma+$ TAMs promote tumor progression through M2 macrophage polarization via BTK-PI3K $\gamma$ signaling. Tumor regression was achieved by administration of ibrutinib, a BTK inhibitor, or PI3K $\gamma$ inhibitors, which reprogrammed TAMs towards an M1 phenotype that fostered CD8+ T cell cytotoxicity [52].

The PI3K $\delta / \gamma$ inhibitor RP6530 was also shown to switch macrophages from an immuno-suppressive M2-like phenotype to a more inflammatory M1-like state. In tumor xenografts of Hodgkin lymphoma, the compound RP6530 repolarized TAMs, inhibited tumor vasculature, and enhanced tumor regression [150].

Histone deacetylases (HDACs) are enzymes that remove the acetyl groups on histones during the process of epigenetic regulation of gene expression. A specific Class IIa HDAC inhibitor (TMP195) has been shown to induce an inflammatory state in monocytes through modification of their epigenomic profile [151]. In a mouse model of breast cancer, the administration of TMP195 induced the recruitment and differentiation of immunostimulatory CD40+ TAMs, resulting in tumor reduction. Moreover, the combination of TMP195 with chemotherapy regimens (carboplatin and paclitaxel) and immunotherapy (anti-PD1 antibodies) significantly enhanced the stability of the tumor response [152].

Interestingly, some investigations using CSF-1R or CCR2 inhibitors showed that the anti-tumor efficacy of these drugs was to reprogram TAMs, rather than macrophage depletion, as supposed previously. For example, CSF-1R or CCR2 inhibition resulted in altered infiltration of myeloid cells by affecting $\mathrm{CD} 11 \mathrm{~b}+\mathrm{Ly6G}-\mathrm{Ly} \mathrm{Cl}^{+} \mathrm{MHCII}^{+} \mathrm{F} 4 / 80+$ macrophages in murine pancreatic cancer models. CSF-1R or CCR2 inhibition, in combination with chemotherapy, resulted in restored CD8+ T cells anti-tumor activity [153]. Interestingly, inhibition of IL-10 receptor in macrophages also reduced tumor burden in breast cancer models if combined with chemotherapy, with an equivalent effect caused by blockade of CSF-1R, in both cases associated with increased IL-12 production by intra-tumor DCs and CD8+ T cell-mediated anti-tumor activity [154]. In mouse glioma models, the CSF-1R inhibitor BLZ945 was effective in treating established tumors and increased mouse survival. Interestingly, the authors found that GM-CSF and IFN $\gamma$ helped TAMs to survive CSF-1R inhibition, leading to the reprogramming of TAMs rather than their depletion [96]. PLX3397 has also been combined with valatinib (inhibitor of VEGF) and dovitinib (inhibitor of FGF receptors) to induce reprogramming of TAMs in glioma [96].

\section{Conclusions}

Although extensive knowledge is available about the characterization and roles of macrophages in solid tumors, there is still room for investigation. The most recent studies have found significant differences in macrophages in distinct tumors, and other investigations have dissected, at the molecular level, the existence of diverse TAM subsets. Following this trend, in the near future, we expect more research to understand in detail the topographical and temporal heterogeneity of specific subsets of macrophages in primary tumors and also in their metastasis. The molecular examination of the mechanisms by which macrophages influence tumor progression and hamper the response to anti-tumor therapies is also a very active field of investigation. In parallel, intense pharmacological research works on the development of strategies to target new relevant molecules are expected. Notably, the increasing importance of macrophages in cancer has prompted scientists to evaluate the interaction of each new drug, but also of "old" pharmacological molecules, on these cells. Indeed, clinical trials using immunotherapies, but also any other kind of oncological treatment, have started to more precisely evaluate treatment efficacy also in the perspective of its effect on the patient's immune system. Altogether, this knowledge will be relevant to design new anti-tumor therapies combining TAM-targeting approaches with other treatments. 
Author Contributions: C.A. and A.U. writing and elaboration of figures; F.T.A. writing and organization of tables; F.T.A. and P.A. writing, review and editing. All authors have read and agreed to the published version of the manuscript.

Funding: This work was supported by the Italian Association for Cancer Research (AIRC $5 \times 1000$ grant no. 21147) and by the European Commission for the 2-INTRATARGET project (EURONANOMEDIII) (P.A.). F.T.A. is the recipient of a grant by the AECC ("Asociación Española Contra el Cáncer, Spain).

Conflicts of Interest: The authors declare no conflicts of interest. The authors certify that they have no affiliations with or involvement in any organization or entity with any financial interest or non-financial interest in the subject matter or materials discussed in this manuscript.

\section{References}

1. Gordon, S.; Plüddemann, A. The Mononuclear Phagocytic System. Generation of Diversity. Front. Immunol. 2019, 10, 1893-1902. [CrossRef]

2. Wynn, T.A.; Chawla, A.; Pollard, J.W. Origins and Hallmarks of Macrophages: Development, Homeostasis, and Disease. Nature 2013, 496, 445-455. [CrossRef]

3. Mantovani, A.; Marchesi, F.; Malesci, A.; Laghi, L.; Allavena, P. Tumour-associated macrophages as treatment targets in oncology. Nat. Rev. Clin. Oncol. 2017, 14, 399-416.

4. Biswas, S.K. Metabolic Reprogramming of Immune Cells in Cancer Progression. Immunity 2015, 43, 435-449. [CrossRef]

5. Mantovani, A.; Sica, A.; Sozzani, S.; Allavena, P.; Vecchi, A.; Locati, M. The chemokine system in diverse forms of macrophage activation and polarization. Trends Immunol. 2004, 25, 677-686. [CrossRef] [PubMed]

6. Yona, S.; Kim, K.-W.; Wolf, Y.; Mildner, A.; Varol, D.; Breker, M.; Strauss-Ayali, D.; Viukov, S.; Guilliams, M.; Misharin, A.; et al. Fate mapping reveals origins and dynamics of monocytes and tissue macrophages under homeostasis. Immunity 2013, 38, 79-91. [CrossRef] [PubMed]

7. Allavena, P.; Mantovani, A. Immunology in the clinic review series; focus on cancer: Tumour-associated macrophages: Undisputed stars of the inflammatory tumour microenvironment. Clin. Exp. Immunol. 2012, 167, 195-205. [CrossRef] [PubMed]

8. De Palma, M.; Lewis, C.E. Macrophage regulation of tumor responses to anticancer therapies. Cancer Cell 2013, 23, 277-286. [CrossRef] [PubMed]

9. Quaranta, V.; Schmid, M.C. Macrophage-Mediated Subversion of Anti-Tumour Immunity. Cells 2019, 8, 747-756.

10. Cortez-Retamozo, V.; Etzrodt, M.; Newton, A.; Rauch, P.J.; Chudnovskiy, A.; Berger, C.; Ryan, R.J.H.; Iwamoto, Y.; Marinelli, B.; Gorbatov, R.; et al. Origins of tumor-associated macrophages and neutrophils. Proc. Natl. Acad. Sci. USA 2012, 109, 2491-2496. [CrossRef] [PubMed]

11. Movahedi, K.; Van Ginderachter, J.A. The Ontogeny and Microenvironmental Regulation of Tumor-Associated Macrophages. Antioxid. Redox Signal. 2016, 25, 775-791. [CrossRef] [PubMed]

12. Vitale, I.; Manic, G.; Coussens, L.M.; Kroemer, G.; Galluzzi, L. Macrophages and Metabolism in the Tumor Microenvironment. Cell Metab. 2019, 30, 36-50. [CrossRef] [PubMed]

13. Lahmar, Q.; Keirsse, J.; Laoui, D.; Movahedi, K.; Van Overmeire, E.; Van Ginderachter, J.A. Tissue-resident versus monocyte-derived macrophages in the tumor microenvironment. Biochim. Biophys. Acta 2016, 1865, 23-34. [CrossRef] [PubMed]

14. Franklin, R.A.; Li, M.O. Ontogeny of Tumor-associated Macrophages and Its Implication in Cancer Regulation. Trends Cancer 2016, 2, 20-34. [CrossRef] [PubMed]

15. Pong, W.W.; Higer, S.B.; Gianino, S.M.; Emnett, R.J.; Gutmann, D.H. Reduced microglial CX3CR1 expression delays neurofibromatosis-1 glioma formation. Ann. Neurol. 2013, 73, 303-308. [CrossRef]

16. Bottazzi, B.; Polentarutti, N.; Acero, R.; Balsari, A.; Boraschi, D.; Ghezzi, P.; Salmona, M.; Mantovani, A. Regulation of the macrophage content of neoplasms by chemoattractants. Science 1983, 220, $210-212$. [CrossRef]

17. Qian, B.-Z.; Li, J.; Zhang, H.; Kitamura, T.; Zhang, J.; Campion, L.R.; Kaiser, E.A.; Snyder, L.A.; Pollard, J.W. CCL2 recruits inflammatory monocytes to facilitate breast tumor metastasis. Nature 2011, 475, $222-225$. [CrossRef]

18. Quail, D.; Joyce, J. Microenvironmental regulation of tumor progression and metastasis. Nat. Med. 2013, 19, 1423-1437. [CrossRef] 
19. Linde, N.; Lederle, W.; Depner, S.; van Rooijen, N.; Gutschalk, C.M.; Mueller, M.M. Vascular endothelial growth factor-induced skin carcinogenesis depends on recruitment and alternative activation of macrophages. J. Pathol. 2012, 227, 17-28. [CrossRef]

20. Thomas, D.A.; Massagué, J. TGF- $\beta$ directly targets cytotoxic T cell functions during tumor evasion of immune surveillance. Cancer Cell 2005, 8, 369-380. [CrossRef]

21. Bohn, T.; Rapp, S.; Luther, N.; Klein, M.; Bruehl, T.-J.; Kojima, N.; Lopez, P.A.; Hahlbrock, J.; Muth, S.; Endo, S.; et al. Tumor immunoevasion via acidosis-dependent induction of regulatory tumor-associated macrophages. Nat. Immunol. 2018, 19, 1319-1329. [CrossRef] [PubMed]

22. Colegio, O.R.; Chu, N.-Q.; Szabo, A.L.; Chu, T.; Rhebergen, A.M.; Jairam, V.; Cyrus, N.; Brokowski, C.E.; Eisenbarth, S.C.; Phillips, G.M.; et al. Functional polarization of tumour-associated macrophages by tumour-derived lactic acid. Nature 2014, 513, 559-563. [CrossRef] [PubMed]

23. Laoui, D.; Van Overmeire, E.; Di Conza, G.; Aldeni, C.; Keirsse, J.; Morias, Y.; Movahedi, K.; Houbracken, I.; Schouppe, E.; Elkrim, Y.; et al. Tumor hypoxia does not drive differentiation of tumor-associated macrophages but rather fine-tunes the M2-like macrophage population. Cancer Res. 2014, 74, 24-30. [CrossRef] [PubMed]

24. Iyer, N.V.; Kotch, L.E.; Agani, F.; Leung, S.W.; Laughner, E.; Wenger, R.H.; Gassmann, M.; Gearhart, J.D.; Lawler, A.M.; Yu, A.Y.; et al. Cellular and developmental control of $\mathrm{O} 2$ homeostasis by hypoxia-inducible factor 1 alpha. Genes Dev. 1998, 12, 149-162. [CrossRef] [PubMed]

25. Sica, A.; Melillo, G.; Varesio, L. Hypoxia: A double-edged sword of immunity. J. Mol. Med. 2011, 89, 657-665. [CrossRef]

26. All 2019 Nobel Prizes. Available online: https://www.nobelprize.org/all-2019-nobel-prizes/ (accessed on 25 November 2019).

27. Hinshaw, D.C.; Shevde, L.A. The Tumor Microenvironment Innately Modulates Cancer Progression. Cancer Res. 2019, 79, 4557-4566. [CrossRef]

28. Wenes, M.; Shang, M.; Di Matteo, M.; Goveia, J.; Martín-Pérez, R.; Serneels, J.; Prenen, H.; Ghesquière, B.; Carmeliet, P.; Mazzone, M. Macrophage Metabolism Controls Tumor Blood Vessel Morphogenesis and Metastasis. Cell Metab. 2016, 24, 701-715. [CrossRef]

29. Cassetta, L.; Pollard, J.W. Targeting macrophages: Therapeutic approaches in cancer. Nat. Rev. Drug Discov. 2018, 17, 887-904. [CrossRef]

30. Mazzieri, R.; Pucci, F.; Moi, D.; Zonari, E.; Ranghetti, A.; Berti, A.; Politi, L.S.; Gentner, B.; Brown, J.L.; Naldini, L.; et al. Targeting the ANG2/TIE2 axis inhibits tumor growth and metastasis by impairing angiogenesis and disabling rebounds of proangiogenic myeloid cells. Cancer Cell 2011, 19, 512-526. [CrossRef]

31. Prenen, H.; Mazzone, M. Tumor-associated macrophages: A short compendium. Cell. Mol. Life Sci. 2019, 76, 1447-1458. [CrossRef]

32. Foekens, J.A.; Peters, H.A.; Look, M.P.; Portengen, H.; Schmitt, M.; Kramer, M.D.; Brünner, N.; Jänicke, F.; Meijer-van Gelder, M.E.; Henzen-Logmans, S.C.; et al. The urokinase system of plasminogen activation and prognosis in 2780 breast cancer patients. Cancer Res. 2000, 60, 636-643. [PubMed]

33. Bonde, A.-K.; Tischler, V.; Kumar, S.; Soltermann, A.; Schwendener, R.A. Intratumoral macrophages contribute to epithelial-mesenchymal transition in solid tumors. BMC Cancer 2012, 12, 35. [CrossRef] [PubMed]

34. Chen, W.; Jin, W.; Hardegen, N.; Lei, K.-J.; Li, L.; Marinos, N.; McGrady, G.; Wahl, S.M. Conversion of peripheral CD4+CD25- naive T cells to CD4+CD25+ regulatory T cells by TGF-beta induction of transcription factor Foxp3. J. Exp. Med. 2003, 198, 1875-1886. [CrossRef] [PubMed]

35. Kim, Y.-J.; Park, S.-J.; Broxmeyer, H.E. Phagocytosis, a potential mechanism for myeloid-derived suppressor cell regulation of CD8+ T cell function mediated through programmed cell death-1 and programmed cell death-1 ligand interaction. J. Immunol. 2011, 187, 2291-2301. [CrossRef]

36. Noman, M.Z.; Desantis, G.; Janji, B.; Hasmim, M.; Karray, S.; Dessen, P.; Bronte, V.; Chouaib, S. PD-L1 is a novel direct target of HIF-1 $\alpha$, and its blockade under hypoxia enhanced MDSC-mediated T cell activation. J. Exp. Med. 2014, 211, 781-790. [CrossRef]

37. Loke, P.; Allison, J.P. PD-L1 and PD-L2 are differentially regulated by Th1 and Th2 cells. Proc. Natl. Acad. Sci. USA 2003, 100, 5336-5341. [CrossRef]

38. Kuang, D.-M.; Zhao, Q.; Peng, C.; Xu, J.; Zhang, J.-P.; Wu, C.; Zheng, L. Activated monocytes in peritumoral stroma of hepatocellular carcinoma foster immune privilege and disease progression through PD-L1. J. Exp. Med. 2009, 206, 1327-1337. [CrossRef] 
39. Bloch, O.; Crane, C.A.; Kaur, R.; Safaee, M.; Rutkowski, M.J.; Parsa, A.T. Gliomas promote immunosuppression through induction of B7-H1 expression in tumor-associated macrophages. Clin. Cancer Res. 2013, 19, 3165-3175. [CrossRef]

40. Winograd, R.; Byrne, K.T.; Evans, R.A.; Odorizzi, P.M.; Meyer, A.R.L.; Bajor, D.L.; Clendenin, C.; Stanger, B.Z.; Furth, E.E.; Wherry, E.J.; et al. Induction of T-cell Immunity Overcomes Complete Resistance to PD-1 and CTLA-4 Blockade and Improves Survival in Pancreatic Carcinoma. Cancer Immunol. Res. 2015, 3, $399-411$. [CrossRef]

41. Candido, J.B.; Morton, J.P.; Bailey, P.; Campbell, A.D.; Karim, S.A.; Jamieson, T.; Lapienyte, L.; Gopinathan, A.; Clark, W.; McGhee, E.J.; et al. CSF1R+ Macrophages Sustain Pancreatic Tumor Growth through T Cell Suppression and Maintenance of Key Gene Programs that Define the Squamous Subtype. Cell Rep. 2018, 23, 1448-1460. [CrossRef]

42. Kalbasi, A.; Ribas, A. Tumour-intrinsic resistance to immune checkpoint blockade. Nat. Rev. Immunol. 2019, 20, 25-39. [CrossRef] [PubMed]

43. Arlauckas, S.P.; Garris, C.S.; Kohler, R.H.; Kitaoka, M.; Cuccarese, M.F.; Yang, K.S.; Miller, M.A.; Carlson, J.C.; Freeman, G.J.; Anthony, R.M.; et al. In vivo imaging reveals a tumor-associated macrophage-mediated resistance pathway in anti-PD-1 therapy. Sci. Transl. Med. 2017, 9, eaal3604. [CrossRef] [PubMed]

44. Gordon, S.R.; Maute, R.L.; Dulken, B.W.; Hutter, G.; George, B.M.; McCracken, M.N.; Gupta, R.; Tsai, J.M.; Sinha, R.; Corey, D.; et al. PD-1 expression by tumour-associated macrophages inhibits phagocytosis and tumour immunity. Nature 2017, 545, 495-499. [CrossRef] [PubMed]

45. Chen, B.J.; Chapuy, B.; Ouyang, J.; Sun, H.H.; Roemer, M.G.M.; Xu, M.L.; Yu, H.; Fletcher, C.D.M.; Freeman, G.J.; Shipp, M.A.; et al. PD-L1 expression is characteristic of a subset of aggressive B-cell lymphomas and virus-associated malignancies. Clin. Cancer Res. 2013, 19, 3462-3473. [CrossRef] [PubMed]

46. Kuklinski, L.F.; Yan, S.; Li, Z.; Fisher, J.L.; Cheng, C.; Noelle, R.J.; Angeles, C.V.; Turk, M.J.; Ernstoff, M.S. VISTA expression on tumor-infiltrating inflammatory cells in primary cutaneous melanoma correlates with poor disease-specific survival. Cancer Immunol. Immunother. 2018, 67, 1113-1121. [CrossRef] [PubMed]

47. Gao, J.; Ward, J.F.; Pettaway, C.A.; Shi, L.Z.; Subudhi, S.K.; Vence, L.M.; Zhao, H.; Chen, J.; Chen, H.; Efstathiou, E.; et al. VISTA is an inhibitory immune checkpoint that is increased after ipilimumab therapy in patients with prostate cancer. Nat. Med. 2017, 23, 551-555. [CrossRef]

48. Uchida, J.; Hamaguchi, Y.; Oliver, J.A.; Ravetch, J.V.; Poe, J.C.; Haas, K.M.; Tedder, T.F. The innate mononuclear phagocyte network depletes B lymphocytes through Fc receptor-dependent mechanisms during anti-CD20 antibody immunotherapy. J. Exp. Med. 2004, 199, 1659-1669. [CrossRef]

49. Kaneda, M.M.; Messer, K.S.; Ralainirina, N.; Li, H.; Leem, C.J.; Gorjestani, S.; Woo, G.; Nguyen, A.V.; Figueiredo, C.C.; Foubert, P.; et al. PI3K $\gamma$ is a molecular switch that controls immune suppression. Nature 2016, 539, 437-442. [CrossRef]

50. Schmid, M.C.; Avraamides, C.J.; Dippold, H.C.; Franco, I.; Foubert, P.; Ellies, L.G.; Acevedo, L.M.; Manglicmot, J.R.E.; Song, X.; Wrasidlo, W.; et al. Receptor tyrosine kinases and TLR/IL1Rs unexpectedly activate myeloid cell PI $3 \mathrm{k} \gamma$, a single convergent point promoting tumor inflammation and progression. Cancer Cell 2011, 19, 715-727. [CrossRef]

51. De Henau, O.; Rausch, M.; Winkler, D.; Campesato, L.F.; Liu, C.; Cymerman, D.H.; Budhu, S.; Ghosh, A.; Pink, M.; Tchaicha, J.; et al. Overcoming resistance to checkpoint blockade therapy by targeting PI3K $\gamma$ in myeloid cells. Nature 2016, 539, 443-447. [CrossRef]

52. Gunderson, A.J.; Kaneda, M.M.; Tsujikawa, T.; Nguyen, A.V.; Affara, N.I.; Ruffell, B.; Gorjestani, S.; Liudahl, S.M.; Truitt, M.; Olson, P.; et al. Bruton's Tyrosine Kinase (BTK)-dependent immune cell crosstalk drives pancreas cancer. Cancer Discov. 2016, 6, 270-285. [CrossRef] [PubMed]

53. Pascual-García, M.; Bonfill-Teixidor, E.; Planas-Rigol, E.; Rubio-Perez, C.; Iurlaro, R.; Arias, A.; Cuartas, I.; Sala-Hojman, A.; Escudero, L.; Martínez-Ricarte, F.; et al. LIF regulates CXCL9 in tumor-associated macrophages and prevents CD8+ T cell tumor-infiltration impairing anti-PD1 therapy. Nat. Commun. 2019, 10, 2416-2430. [CrossRef] [PubMed]

54. Rashidian, M.; LaFleur, M.W.; Verschoor, V.L.; Dongre, A.; Zhang, Y.; Nguyen, T.H.; Kolifrath, S.; Aref, A.R.; Lau, C.J.; Paweletz, C.P.; et al. Immuno-PET identifies the myeloid compartment as a key contributor to the outcome of the antitumor response under PD-1 blockade. Proc. Natl. Acad. Sci. USA 2019, 116, 16971-16980. [CrossRef] [PubMed] 
55. Peranzoni, E.; Lemoine, J.; Vimeux, L.; Feuillet, V.; Barrin, S.; Kantari-Mimoun, C.; Bercovici, N.; Guérin, M.; Biton, J.; Ouakrim, H.; et al. Macrophages impede CD8 T cells from reaching tumor cells and limit the efficacy of anti-PD-1 treatment. Proc. Natl. Acad. Sci. USA 2018, 115, E4041-E4050. [CrossRef] [PubMed]

56. Mantovani, A.; Allavena, P. The interaction of anticancer therapies with tumor-associated macrophages. J. Exp. Med. 2015, 212, 435-445. [CrossRef] [PubMed]

57. Kroemer, G.; Galluzzi, L.; Kepp, O.; Zitvogel, L. Immunogenic cell death in cancer therapy. Annu. Rev. Immunol. 2013, 31, 51-72. [CrossRef] [PubMed]

58. Colotta, F.; Peri, G.; Villa, A.; Mantovani, A. Rapid killing of actinomycin D-treated tumor cells by human mononuclear cells. I. Effectors belong to the monocyte-macrophage lineage. J. Immunol. 1984, 132, 936-944.

59. Di Caro, G.; Cortese, N.; Castino, G.F.; Grizzi, F.; Gavazzi, F.; Ridolfi, C.; Capretti, G.; Mineri, R.; Todoric, J.; Zerbi, A.; et al. Dual prognostic significance of tumour-associated macrophages in human pancreatic adenocarcinoma treated or untreated with chemotherapy. Gut 2016, 65, 1710-1720. [CrossRef]

60. DeNardo, D.G.; Brennan, D.J.; Rexhepaj, E.; Ruffell, B.; Shiao, S.L.; Madden, S.F.; Gallagher, W.M.; Wadhwani, N.; Keil, S.D.; Junaid, S.A.; et al. Leukocyte Complexity Predicts Breast Cancer Survival and Functionally Regulates Response to Chemotherapy. Cancer Discov. 2011, 1, 54-67. [CrossRef]

61. Nakasone, E.S.; Askautrud, H.A.; Kees, T.; Park, J.-H.; Plaks, V.; Ewald, A.J.; Fein, M.; Rasch, M.G.; Tan, Y.-X.; Qiu, J.; et al. Imaging tumor-stroma interactions during chemotherapy reveals contributions of the microenvironment to resistance. Cancer Cell 2012, 21, 488-503. [CrossRef]

62. Zhang, X.; Chen, Y.; Hao, L.; Hou, A.; Chen, X.; Li, Y.; Wang, R.; Luo, P.; Ruan, Z.; Ou, J.; et al. Macrophages induce resistance to 5 -fluorouracil chemotherapy in colorectal cancer through the release of putrescine. Cancer Lett. 2016, 381, 305-313. [CrossRef] [PubMed]

63. Salvagno, C.; Ciampricotti, M.; Tuit, S.; Hau, C.-S.; van Weverwijk, A.; Coffelt, S.B.; Kersten, K.; Vrijland, K.; Kos, K.; Ulas, T.; et al. Therapeutic targeting of macrophages enhances chemotherapy efficacy by unleashing type I interferon response. Nat. Cell Biol. 2019, 21, 511-521. [CrossRef] [PubMed]

64. Houthuijzen, J.M.; Daenen, L.G.M.; Roodhart, J.M.L.; Oosterom, I.; van Jaarsveld, M.T.M.; Govaert, K.M.; Smith, M.E.; Sadatmand, S.J.; Rosing, H.; Kruse, F.; et al. Lysophospholipids secreted by splenic macrophages induce chemotherapy resistance via interference with the DNA damage response. Nat. Commun. 2014, 5, 5275. [CrossRef] [PubMed]

65. Ruffell, B.; Coussens, L.M. Macrophages and therapeutic resistance in cancer. Cancer Cell 2015, 27, 462-472. [CrossRef]

66. Shojaei, F.; Wu, X.; Malik, A.K.; Zhong, C.; Baldwin, M.E.; Schanz, S.; Fuh, G.; Gerber, H.-P.; Ferrara, N. Tumor refractoriness to anti-VEGF treatment is mediated by CD11b+Gr1+ myeloid cells. Nat. Biotechnol. 2007, 25, 911-920. [CrossRef]

67. Dalton, H.J.; Pradeep, S.; McGuire, M.; Hailemichael, Y.; Ma, S.; Lyons, Y.; Armaiz-Pena, G.N.; Previs, R.A.; Hansen, J.M.; Rupaimoole, R.; et al. Macrophages Facilitate Resistance to Anti-VEGF Therapy by Altered VEGFR Expression. Clin. Cancer Res. 2017, 23, 7034-7046. [CrossRef]

68. Achyut, B.R.; Shankar, A.; Iskander, A.S.M.; Ara, R.; Angara, K.; Zeng, P.; Knight, R.A.; Scicli, A.G.; Arbab, A.S. Bone marrow derived myeloid cells orchestrate antiangiogenic resistance in glioblastoma through coordinated molecular networks. Cancer Lett. 2015, 369, 416-426. [CrossRef]

69. Kloepper, J.; Riedemann, L.; Amoozgar, Z.; Seano, G.; Susek, K.; Yu, V.; Dalvie, N.; Amelung, R.L.; Datta, M.; Song, J.W.; et al. Ang-2/VEGF bispecific antibody reprograms macrophages and resident microglia to anti-tumor phenotype and prolongs glioblastoma survival. Proc. Natl. Acad. Sci. USA 2016, 113, 4476-4481. [CrossRef]

70. Leblond, M.M.; Pérès, E.A.; Helaine, C.; Gérault, A.N.; Moulin, D.; Anfray, C.; Divoux, D.; Petit, E.; Bernaudin, M.; Valable, S. M2 macrophages are more resistant than M1 macrophages following radiation therapy in the context of glioblastoma. Oncotarget 2017, 8, 72597-72612. [CrossRef]

71. Teresa Pinto, A.; Laranjeiro Pinto, M.; Patrícia Cardoso, A.; Monteiro, C.; Teixeira Pinto, M.; Filipe Maia, A.; Castro, P.; Figueira, R.; Monteiro, A.; Marques, M.; et al. Ionizing radiation modulates human macrophages towards a pro-inflammatory phenotype preserving their pro-invasive and pro-angiogenic capacities. Sci. Rep. 2016, 6, 18765. [CrossRef]

72. Meng, Y.; Beckett, M.A.; Liang, H.; Mauceri, H.J.; van Rooijen, N.; Cohen, K.S.; Weichselbaum, R.R. Blockade of tumor necrosis factor alpha signaling in tumor-associated macrophages as a radiosensitizing strategy. Cancer Res. 2010, 70, 1534-1543. [CrossRef] 
73. Klug, F.; Prakash, H.; Huber, P.E.; Seibel, T.; Bender, N.; Halama, N.; Pfirschke, C.; Voss, R.H.; Timke, C.; Umansky, L.; et al. Low-dose irradiation programs macrophage differentiation to an $\mathrm{NOS}^{+} / \mathrm{M} 1$ phenotype that orchestrates effective $\mathrm{T}$ cell immunotherapy. Cancer Cell 2013, 24, 589-602. [CrossRef]

74. Nadella, V.; Singh, S.; Jain, A.; Jain, M.; Vasquez, K.M.; Sharma, A.; Tanwar, P.; Rath, G.K.; Prakash, H. Low dose radiation primed iNOS + M1macrophages modulate angiogenic programming of tumor derived endothelium. Mol. Carcinog. 2018, 57, 1664-1671. [CrossRef]

75. Canè, S.; Ugel, S.; Trovato, R.; Marigo, I.; De Sanctis, F.; Sartoris, S.; Bronte, V. The Endless Saga of Monocyte Diversity. Front. Immunol. 2019, 10, 1786-1797. [CrossRef]

76. Argyle, D.; Kitamura, T. Targeting Macrophage-Recruiting Chemokines as a Novel Therapeutic Strategy to Prevent the Progression of Solid Tumors. Front. Immunol. 2018, 9, 2629-2639. [CrossRef]

77. Brana, I.; Calles, A.; LoRusso, P.M.; Yee, L.K.; Puchalski, T.A.; Seetharam, S.; Zhong, B.; de Boer, C.J.; Tabernero, J.; Calvo, E. Carlumab, an anti-C-C chemokine ligand 2 monoclonal antibody, in combination with four chemotherapy regimens for the treatment of patients with solid tumors: An open-label, multicenter phase 1b study. Target Oncol. 2015, 10, 111-123. [CrossRef]

78. Bonapace, L.; Coissieux, M.-M.; Wyckoff, J.; Mertz, K.D.; Varga, Z.; Junt, T.; Bentires-Alj, M. Cessation of CCL2 inhibition accelerates breast cancer metastasis by promoting angiogenesis. Nature 2014, 515, 130-133. [CrossRef]

79. Hughes, R.; Qian, B.-Z.; Rowan, C.; Muthana, M.; Keklikoglou, I.; Olson, O.C.; Tazzyman, S.; Danson, S.; Addison, C.; Clemons, M.; et al. Perivascular M2 Macrophages Stimulate Tumor Relapse after Chemotherapy. Cancer Res. 2015, 75, 3479-3491. [CrossRef]

80. Sánchez-Martín, L.; Estecha, A.; Samaniego, R.; Sánchez-Ramón, S.; Vega, M.Á.; Sánchez-Mateos, P. The chemokine CXCL12 regulates monocyte-macrophage differentiation and RUNX3 expression. Blood 2011, 117, 88-97. [CrossRef]

81. Boimel, P.J.; Smirnova, T.; Zhou, Z.N.; Wyckoff, J.; Park, H.; Coniglio, S.J.; Qian, B.-Z.; Stanley, E.R.; Cox, D.; Pollard, J.W.; et al. Contribution of CXCL12 secretion to invasion of breast cancer cells. Breast Cancer Res. 2012, 14, R23. [CrossRef]

82. Ludwig, H.; Weisel, K.; Petrucci, M.T.; Leleu, X.; Cafro, A.M.; Garderet, L.; Leitgeb, C.; Foa, R.; Greil, R.; Yakoub-Agha, I.; et al. Olaptesed pegol, an anti-CXCL12/SDF-1 Spiegelmer, alone and with bortezomib-dexamethasone in relapsed/refractory multiple myeloma: A Phase IIa Study. Leukemia 2017, 31, 997-1000. [CrossRef]

83. Koh, Y.W.; Park, C.; Yoon, D.H.; Suh, C.; Huh, J. CSF-1R expression in tumor-associated macrophages is associated with worse prognosis in classical Hodgkin lymphoma. Am. J. Clin. Pathol. 2014, 141, 573-583. [CrossRef]

84. Zhu, X.-D.; Zhang, J.-B.; Zhuang, P.-Y.; Zhu, H.-G.; Zhang, W.; Xiong, Y.-Q.; Wu, W.-Z.; Wang, L.; Tang, Z.-Y.; Sun, H.-C. High expression of macrophage colony-stimulating factor in peritumoral liver tissue is associated with poor survival after curative resection of hepatocellular carcinoma. J. Clin. Oncol. 2008, 26, 2707-2716. [CrossRef]

85. Goswami, S.; Sahai, E.; Wyckoff, J.B.; Cammer, M.; Cox, D.; Pixley, F.J.; Stanley, E.R.; Segall, J.E.; Condeelis, J.S. Macrophages promote the invasion of breast carcinoma cells via a colony-stimulating factor-1/epidermal growth factor paracrine loop. Cancer Res. 2005, 65, 5278-5283. [CrossRef]

86. Lin, E.Y.; Nguyen, A.V.; Russell, R.G.; Pollard, J.W. Colony-stimulating factor 1 promotes progression of mammary tumors to malignancy. J. Exp. Med. 2001, 193, 727-740. [CrossRef]

87. Ries, C.H.; Cannarile, M.A.; Hoves, S.; Benz, J.; Wartha, K.; Runza, V.; Rey-Giraud, F.; Pradel, L.P.; Feuerhake, F.; Klaman, I.; et al. Targeting tumor-associated macrophages with anti-CSF-1R antibody reveals a strategy for cancer therapy. Cancer Cell 2014, 25, 846-859. [CrossRef]

88. Gomez-Roca, C.A.; Italiano, A.; Le Tourneau, C.; Cassier, P.A.; Toulmonde, M.; D'Angelo, S.P.; Campone, M.; Weber, K.L.; Loirat, D.; Cannarile, M.A.; et al. Phase I Study of Emactuzumab Single Agent or in Combination with Paclitaxel in Patients with Advanced/Metastatic Solid Tumors Reveals Depletion of Immunosuppressive M2-like Macrophages. Ann. Oncol. 2019, 30, 1381-1392. [CrossRef]

89. Wesolowski, R.; Sharma, N.; Reebel, L.; Rodal, M.B.; Peck, A.; West, B.L.; Marimuthu, A.; Severson, P.; Karlin, D.A.; Dowlati, A.; et al. Phase Ib study of the combination of pexidartinib (PLX3397), a CSF-1R inhibitor, and paclitaxel in patients with advanced solid tumors. Ther. Adv. Med. Oncol. 2019, 11, 1758835919854238. [CrossRef] 
90. Strachan, D.C.; Ruffell, B.; Oei, Y.; Bissell, M.J.; Coussens, L.M.; Pryer, N.; Daniel, D. CSF1R inhibition delays cervical and mammary tumor growth in murine models by attenuating the turnover of tumor-associated macrophages and enhancing infiltration by CD8+ T cells. Oncoimmunology 2013, 2, e26968. [CrossRef]

91. Xu, J.; Escamilla, J.; Mok, S.; David, J.; Priceman, S.; West, B.; Bollag, G.; McBride, W.; Wu, L. CSF1R signaling blockade stanches tumor-infiltrating myeloid cells and improves the efficacy of radiotherapy in prostate cancer. Cancer Res. 2013, 73, 2782-2794. [CrossRef]

92. Zhu, Y.; Knolhoff, B.L.; Meyer, M.A.; Nywening, T.M.; West, B.L.; Luo, J.; Wang-Gillam, A.; Goedegebuure, S.P.; Linehan, D.C.; DeNardo, D.G. CSF1/CSF1R blockade reprograms tumor-infiltrating macrophages and improves response to T-cell checkpoint immunotherapy in pancreatic cancer models. Cancer Res. 2014, 74, 5057-5069. [CrossRef]

93. Patwardhan, P.P.; Surriga, O.; Beckman, M.J.; de Stanchina, E.; Dematteo, R.P.; Tap, W.D.; Schwartz, G.K. Sustained inhibition of receptor tyrosine kinases and macrophage depletion by PLX3397 and rapamycin as a potential new approach for the treatment of MPNSTs. Clin. Cancer Res. 2014, 20, 3146-3158. [CrossRef]

94. Mok, S.; Tsoi, J.; Koya, R.C.; Hu-Lieskovan, S.; West, B.L.; Bollag, G.; Graeber, T.G.; Ribas, A. Inhibition of colony stimulating factor-1 receptor improves antitumor efficacy of BRAF inhibition. BMC Cancer 2015, 15, 356. [CrossRef]

95. Quaranta, V.; Rainer, C.; Nielsen, S.R.; Raymant, M.L.; Ahmed, M.S.; Engle, D.D.; Taylor, A.; Murray, T.; Campbell, F.; Palmer, D.H.; et al. Macrophage-Derived Granulin Drives Resistance to Immune Checkpoint Inhibition in Metastatic Pancreatic Cancer. Cancer Res. 2018, 78, 4253-4269. [CrossRef]

96. Pyonteck, S.M.; Akkari, L.; Schuhmacher, A.J.; Bowman, R.L.; Sevenich, L.; Quail, D.F.; Olson, O.C.; Quick, M.L.; Huse, J.T.; Teijeiro, V.; et al. CSF-1R inhibition alters macrophage polarization and blocks glioma progression. Nat. Med. 2013, 19, 1264-1272. [CrossRef]

97. Stafford, J.H.; Hirai, T.; Deng, L.; Chernikova, S.B.; Urata, K.; West, B.L.; Brown, J.M. Colony stimulating factor 1 receptor inhibition delays recurrence of glioblastoma after radiation by altering myeloid cell recruitment and polarization. Neuro Oncol. 2016, 18, 797-806. [CrossRef]

98. Kalbasi, A.; Komar, C.; Tooker, G.M.; Liu, M.; Lee, J.W.; Gladney, W.L.; Ben-Josef, E.; Beatty, G.L. Tumor-Derived CCL2 Mediates Resistance to Radiotherapy in Pancreatic Ductal Adenocarcinoma. Clin. Cancer Res. 2017, 23, 137-148. [CrossRef]

99. Piaggio, F.; Kondylis, V.; Pastorino, F.; Di Paolo, D.; Perri, P.; Cossu, I.; Schorn, F.; Marinaccio, C.; Murgia, D.; Daga, A.; et al. A novel liposomal Clodronate depletes tumor-associated macrophages in primary and metastatic melanoma: Anti-angiogenic and anti-tumor effects. J. Control. Release 2016, 223, 165-177. [CrossRef]

100. Zhu, S.; Niu, M.; O'Mary, H.; Cui, Z. Targeting of tumor-associated macrophages made possible by PEG-sheddable, mannose-modified nanoparticles. Mol. Pharm. 2013, 10, 3525-3530. [CrossRef]

101. Germano, G.; Frapolli, R.; Belgiovine, C.; Anselmo, A.; Pesce, S.; Liguori, M.; Erba, E.; Uboldi, S.; Zucchetti, M.; Pasqualini, F; et al. Role of macrophage targeting in the antitumor activity of trabectedin. Cancer Cell 2013, 23, 249-262. [CrossRef]

102. Banerjee, P.; Zhang, R.; Ivan, C.; Galletti, G.; Clise-Dwyer, K.; Barbaglio, F.; Scarfò, L.; Aracil, M.; Klein, C.; Wierda, W.; et al. Trabectedin Reveals a Strategy of Immunomodulation in Chronic Lymphocytic Leukemia. Cancer Immunol. Res. 2019, 7, 2036-2051. [CrossRef] [PubMed]

103. Jones, J.D.; Sinder, B.P.; Paige, D.; Soki, F.N.; Koh, A.J.; Thiele, S.; Shiozawa, Y.; Hofbauer, L.C.; Daignault, S.; Roca, H.; et al. Trabectedin Reduces Skeletal Prostate Cancer Tumor Size in Association with Effects on M2 Macrophages and Efferocytosis. Neoplasia 2019, 21, 172-184. [CrossRef] [PubMed]

104. Carminati, L.; Pinessi, D.; Borsotti, P.; Minoli, L.; Giavazzi, R.; D’Incalci, M.; Belotti, D.; Taraboletti, G. Antimetastatic and antiangiogenic activity of trabectedin in cutaneous melanoma. Carcinogenesis 2019, 40, 303-312. [CrossRef] [PubMed]

105. Borgoni, S.; Iannello, A.; Cutrupi, S.; Allavena, P.; D'Incalci, M.; Novelli, F.; Cappello, P. Depletion of tumor-associated macrophages switches the epigenetic profile of pancreatic cancer infiltrating $\mathrm{T}$ cells and restores their anti-tumor phenotype. OncoImmunology 2018, 7, e1393596. [CrossRef] [PubMed]

106. Kielbassa, K.; Vegna, S.; Ramirez, C.; Akkari, L. Understanding the Origin and Diversity of Macrophages to Tailor Their Targeting in Solid Cancers. Front. Immunol. 2019, 10, 2215-2231. [CrossRef] [PubMed] 
107. Shiraishi, D.; Fujiwara, Y.; Horlad, H.; Saito, Y.; Iriki, T.; Tsuboki, J.; Cheng, P.; Nakagata, N.; Mizuta, H.; Bekki, H.; et al. CD163 Is Required for Protumoral Activation of Macrophages in Human and Murine Sarcoma. Cancer Res. 2018, 78, 3255-3266. [CrossRef] [PubMed]

108. Pinto, M.L.; Rios, E.; Durães, C.; Ribeiro, R.; Machado, J.C.; Mantovani, A.; Barbosa, M.A.; Carneiro, F.; Oliveira, M.J. The Two Faces of Tumor-Associated Macrophages and Their Clinical Significance in Colorectal Cancer. Front. Immunol. 2019, 10, 1875. [CrossRef]

109. Etzerodt, A.; Tsalkitzi, K.; Maniecki, M.; Damsky, W.; Delfini, M.; Baudoin, E.; Moulin, M.; Bosenberg, M.; Graversen, J.H.; Auphan-Anezin, N.; et al. Specific targeting of CD163+ TAMs mobilizes inflammatory monocytes and promotes T cell-mediated tumor regression. J. Exp. Med. 2019, 216, 2394-2411. [CrossRef]

110. Quail, D.F.; Bowman, R.L.; Akkari, L.; Quick, M.L.; Schuhmacher, A.J.; Huse, J.T.; Holland, E.C.; Sutton, J.C.; Joyce, J.A. The tumor microenvironment underlies acquired resistance to CSF-1R inhibition in gliomas. Science 2016, 352, aad3018. [CrossRef]

111. Kumar, V.; Donthireddy, L.; Marvel, D.; Condamine, T.; Wang, F.; Lavilla-Alonso, S.; Hashimoto, A.; Vonteddu, P.; Behera, R.; Goins, M.A.; et al. Cancer-Associated Fibroblasts Neutralize the Anti-tumor Effect of CSF1 Receptor Blockade by Inducing PMN-MDSC Infiltration of Tumors. Cancer Cell 2017, 32, 654-668. [CrossRef]

112. Maeda, A.; Digifico, E.; Andon, F.T.; Mantovani, A.; Allavena, P. Poly(I:C) stimulation is superior than Imiquimod to induce the antitumoral functional profile of tumor-conditioned macrophages. Eur. J. Immunol. 2019, 49, 801-811. [CrossRef] [PubMed]

113. Vidyarthi, A.; Khan, N.; Agnihotri, T.; Negi, S.; Das, D.K.; Aqdas, M.; Chatterjee, D.; Colegio, O.R.; Tewari, M.K.; Agrewala, J.N. TLR-3 Stimulation Skews M2 Macrophages to M1 Through IFN- $\alpha \beta$ Signaling and Restricts Tumor Progression. Front. Immunol. 2018, 9, 1650. [CrossRef] [PubMed]

114. Shime, H.; Matsumoto, M.; Oshiumi, H.; Tanaka, S.; Nakane, A.; Iwakura, Y.; Tahara, H.; Inoue, N.; Seya, T. Toll-like receptor 3 signaling converts tumor-supporting myeloid cells to tumoricidal effectors. Proc. Natl. Acad. Sci. USA 2012, 109, 2066-2071. [CrossRef] [PubMed]

115. Liu, L.; He, H.; Liang, R.; Yi, H.; Meng, X.; Chen, Z.; Pan, H.; Ma, Y.; Cai, L. ROS-Inducing Micelles Sensitize Tumor-Associated Macrophages to TLR3 Stimulation for Potent Immunotherapy. Biomacromolecules 2018, 19, 2146-2155. [CrossRef]

116. Zanganeh, S.; Hutter, G.; Spitler, R.; Lenkov, O.; Mahmoudi, M.; Shaw, A.; Pajarinen, J.S.; Nejadnik, H.; Goodman, S.; Moseley, M.; et al. Iron oxide nanoparticles inhibit tumour growth by inducing pro-inflammatory macrophage polarization in tumour tissues. Nat. Nanotechnol. 2016, 11, 986-994. [CrossRef]

117. Zhao, J.; Zhang, Z.; Xue, Y.; Wang, G.; Cheng, Y.; Pan, Y.; Zhao, S.; Hou, Y. Anti-tumor macrophages activated by ferumoxytol combined or surface-functionalized with the TLR3 agonist poly (I : C) promote melanoma regression. Theranostics 2018, 8, 6307-6321. [CrossRef]

118. Thauvin, C.; Widmer, J.; Mottas, I.; Hocevar, S.; Allémann, E.; Bourquin, C.; Delie, F. Development of resiquimod-loaded modified PLA-based nanoparticles for cancer immunotherapy: A kinetic study. Eur. J. Pharm. Biopharm. 2019, 139, 253-261. [CrossRef]

119. Chi, H.; Li, C.; Zhao, F.S.; Zhang, L.; Ng, T.B.; Jin, G.; Sha, O. Anti-tumor Activity of Toll-Like Receptor 7 Agonists. Front. Pharmacol. 2017, 8, 304-312. [CrossRef]

120. Huang, L.; Xu, H.; Peng, G. TLR-mediated metabolic reprogramming in the tumor microenvironment: Potential novel strategies for cancer immunotherapy. Cell Mol. Immunol. 2018, 15, 428-437. [CrossRef]

121. Perkins, H.; Khodai, T.; Mechiche, H.; Colman, P.; Burden, F.; Laxton, C.; Horscroft, N.; Corey, T.; Rodrigues, D.; Rawal, J.; et al. Therapy with TLR7 agonists induces lymphopenia: Correlating pharmacology to mechanism in a mouse model. J. Clin. Immunol. 2012, 32, 1082-1092. [CrossRef]

122. Hasham, M.G.; Baxan, N.; Stuckey, D.J.; Branca, J.; Perkins, B.; Dent, O.; Duffy, T.; Hameed, T.S.; Stella, S.E.; Bellahcene, M.; et al. Systemic autoimmunity induced by the TLR7/8 agonist Resiquimod causes myocarditis and dilated cardiomyopathy in a new mouse model of autoimmune heart disease. Dis. Model Mech. 2017, 10, 259-270. [CrossRef] [PubMed]

123. Mullins, S.R.; Vasilakos, J.P.; Deschler, K.; Grigsby, I.; Gillis, P.; John, J.; Elder, M.J.; Swales, J.; Timosenko, E.; Cooper, Z.; et al. Intratumoral immunotherapy with TLR7/8 agonist MEDI9197 modulates the tumor microenvironment leading to enhanced activity when combined with other immunotherapies. J. Immunother. Cancer 2019, 7, 244. [CrossRef] [PubMed] 
124. Rodell, C.B.; Arlauckas, S.P.; Cuccarese, M.F.; Garris, C.S.; Li, R.; Ahmed, M.S.; Kohler, R.H.; Pittet, M.J.; Weissleder, R. TLR7/8-agonist-loaded nanoparticles promote the polarization of tumour-associated macrophages to enhance cancer immunotherapy. Nat. Biomed. Eng. 2018, 2, 578-590. [CrossRef]

125. Liu, B.; Liu, Q.; Yang, L.; Palaniappan, S.K.; Bahar, I.; Thiagarajan, P.S.; Ding, J.L. Innate immune memory and homeostasis may be conferred through crosstalk between the TLR3 and TLR7 pathways. Sci. Signal 2016, 9, ra70. [CrossRef] [PubMed]

126. Bocanegra Gondan, A.I.; Ruiz-de-Angulo, A.; Zabaleta, A.; Gómez Blanco, N.; Cobaleda-Siles, B.M.; García-Granda, M.J.; Padro, D.; Llop, J.; Arnaiz, B.; Gato, M.; et al. Effective cancer immunotherapy in mice by polyIC-imiquimod complexes and engineered magnetic nanoparticles. Biomaterials 2018, 170, 95-115. [CrossRef] [PubMed]

127. Da Silva, C.G.; Camps, M.G.M.; Li, T.M.W.Y.; Chan, A.B.; Ossendorp, F.; Cruz, L.J. Co-delivery of immunomodulators in biodegradable nanoparticles improves therapeutic efficacy of cancer vaccines. Biomaterials 2019, 220, 119417. [CrossRef]

128. Liu, Z.; Xie, Y.; Xiong, Y.; Liu, S.; Qiu, C.; Zhu, Z.; Mao, H.; Yu, M.; Wang, X. TLR 7/8 agonist reverses oxaliplatin resistance in colorectal cancer via directing the myeloid-derived suppressor cells to tumoricidal M1-macrophages. Cancer Lett. 2019, 469, 173-185. [CrossRef]

129. Phuengkham, H.; Song, C.; Lim, Y.T. A Designer Scaffold with Immune Nanoconverters for Reverting Immunosuppression and Enhancing Immune Checkpoint Blockade Therapy. Adv. Mater. Weinh. 2019, 31, e1903242. [CrossRef]

130. McKinlay, C.J.; Vargas, J.R.; Blake, T.R.; Hardy, J.W.; Kanada, M.; Contag, C.H.; Wender, P.A.; Waymouth, R.M. Charge-altering releasable transporters (CARTs) for the delivery and release of mRNA in living animals. PNAS 2017, 114, E448-E456. [CrossRef]

131. Haabeth, O.A.W.; Blake, T.R.; McKinlay, C.J.; Tveita, A.A.; Sallets, A.; Waymouth, R.M.; Wender, P.A.; Levy, R. Local Delivery of Ox401, Cd80, and Cd86 mRNA Kindles Global Anticancer Immunity. Cancer Res. 2019, 79, 1624-1634. [CrossRef]

132. Zhang, F.; Parayath, N.N.; Ene, C.I.; Stephan, S.B.; Koehne, A.L.; Coon, M.E.; Holland, E.C.; Stephan, M.T. Genetic programming of macrophages to perform anti-tumor functions using targeted mRNA nanocarriers. Nat. Commun. 2019, 10, 3974. [CrossRef] [PubMed]

133. Jia, N.; Wu, H.; Duan, J.; Wei, C.; Wang, K.; Zhang, Y.; Mao, X. Polyethyleneimine-coated Iron Oxide Nanoparticles as a Vehicle for the Delivery of Small Interfering RNA to Macrophages In Vitro and In Vivo. J. Vis. Exp. 2019, 144, e58660. [CrossRef] [PubMed]

134. Liang, S.; Zheng, J.; Wu, W.; Li, Q.; Saw, P.E.; Chen, J.; Xu, X.; Yao, H.; Yao, Y. A Robust Nanoparticle Platform for RNA Interference in Macrophages to Suppress Tumor Cell Migration. Front. Pharmacol. 2018, 9, 1465. [CrossRef] [PubMed]

135. Song, Y.; Tang, C.; Yin, C. Combination antitumor immunotherapy with VEGF and PIGF siRNA via systemic delivery of multi-functionalized nanoparticles to tumor-associated macrophages and breast cancer cells. Biomaterials 2018, 185, 117-132. [CrossRef] [PubMed]

136. Cai, X.; Yin, Y.; Li, N.; Zhu, D.; Zhang, J.; Zhang, C.-Y.; Zen, K. Re-polarization of tumor-associated macrophages to pro-inflammatory M1 macrophages by microRNA-155. J. Mol. Cell Biol. 2012, 4, 341-343. [CrossRef] [PubMed]

137. Zang, X.; Zhang, X.; Hu, H.; Qiao, M.; Zhao, X.; Deng, Y.; Chen, D. Targeted Delivery of Zoledronate to Tumor-Associated Macrophages for Cancer Immunotherapy. Mol. Pharm. 2019, 16, 2249-2258. [CrossRef] [PubMed]

138. Murata, Y.; Kotani, T.; Ohnishi, H.; Matozaki, T. The CD47-SIRP $\alpha$ signalling system: Its physiological roles and therapeutic application. J. Biochem. 2014, 155, 335-344. [CrossRef]

139. Yang, H.; Shao, R.; Huang, H.; Wang, X.; Rong, Z.; Lin, Y. Engineering macrophages to phagocytose cancer cells by blocking the CD47/SIRP $\alpha$ axis. Cancer Med. 2019, 8, 4245-4253.

140. Gu, S.; Ni, T.; Wang, J.; Liu, Y.; Fan, Q.; Wang, Y.; Huang, T.; Chu, Y.; Sun, X.; Wang, Y. CD47 Blockade Inhibits Tumor Progression through Promoting Phagocytosis of Tumor Cells by M2 Polarized Macrophages in Endometrial Cancer. J. Immunol. Res. 2018, 2018, 6156757. [CrossRef]

141. Noman, M.Z.; Van Moer, K.; Marani, V.; Gemmill, R.M.; Tranchevent, L.-C.; Azuaje, F.; Muller, A.; Chouaib, S.; Thiery, J.P.; Berchem, G.; et al. CD47 is a direct target of SNAI1 and ZEB1 and its blockade activates the phagocytosis of breast cancer cells undergoing EMT. Oncoimmunology 2018, 7, e1345415. [CrossRef] 
142. Kulkarni, A.; Chandrasekar, V.; Natarajan, S.K.; Ramesh, A.; Pandey, P.; Nirgud, J.; Bhatnagar, H.; Ashok, D.; Ajay, A.K.; Sengupta, S. A designer self-assembled supramolecule amplifies macrophage immune responses against aggressive cancer. Nat. Biomed. Eng. 2018, 2, 589-599. [CrossRef] [PubMed]

143. Ramesh, A.; Kumar, S.; Nandi, D.; Kulkarni, A. CSF1R- and SHP2-Inhibitor-Loaded Nanoparticles Enhance Cytotoxic Activity and Phagocytosis in Tumor-Associated Macrophages. Adv. Mater. Weinh. 2019, e1904364. [CrossRef] [PubMed]

144. Advani, R.; Flinn, I.; Popplewell, L.; Forero, A.; Bartlett, N.L.; Ghosh, N.; Kline, J.; Roschewski, M.; LaCasce, A.; Collins, G.P.; et al. CD47 Blockade by Hu5F9-G4 and Rituximab in Non-Hodgkin's Lymphoma. N. Engl. J. Med. 2018, 379, 1711-1721. [CrossRef] [PubMed]

145. Zhang, J.Q.; Zeng, S.; Vitiello, G.A.; Seifert, A.M.; Medina, B.D.; Beckman, M.J.; Loo, J.K.; Santamaria-Barria, J.; Maltbaek, J.H.; Param, N.J.; et al. Macrophages and CD8+ T Cells Mediate the Antitumor Efficacy of Combined CD40 Ligation and Imatinib Therapy in Gastrointestinal Stromal Tumors. Cancer Immunol. Res. 2018, 6, 434-447. [CrossRef] [PubMed]

146. Beatty, G.L.; Chiorean, E.G.; Fishman, M.P.; Saboury, B.; Teitelbaum, U.R.; Sun, W.; Huhn, R.D.; Song, W.; Li, D.; Sharp, L.L.; et al. CD40 agonists alter tumor stroma and show efficacy against pancreatic carcinoma in mice and humans. Science 2011, 331, 1612-1616. [CrossRef] [PubMed]

147. Perry, C.J.; Muñoz-Rojas, A.R.; Meeth, K.M.; Kellman, L.N.; Amezquita, R.A.; Thakral, D.; Du, V.Y.; Wang, J.X.; Damsky, W.; Kuhlmann, A.L.; et al. Myeloid-targeted immunotherapies act in synergy to induce inflammation and antitumor immunity. J. Exp. Med. 2018, 215, 877-893. [CrossRef] [PubMed]

148. Vonderheide, R.H. CD40 Agonist Antibodies in Cancer Immunotherapy. Annu. Rev. Med. $2019,71$. [CrossRef]

149. Wiehagen, K.R.; Girgis, N.M.; Yamada, D.H.; Smith, A.A.; Chan, S.R.; Grewal, I.S.; Quigley, M.; Verona, R.I. Combination of CD40 Agonism and CSF-1R Blockade Reconditions Tumor-Associated Macrophages and Drives Potent Antitumor Immunity. Cancer Immunol. Res. 2017, 5, 1109-1121. [CrossRef]

150. Locatelli, S.L.; Careddu, G.; Serio, S.; Consonni, F.M.; Maeda, A.; Viswanadha, S.; Vakkalanka, S.; Castagna, L.; Santoro, A.; Allavena, P.; et al. Targeting Cancer Cells and Tumor Microenvironment in Preclinical and Clinical Models of Hodgkin Lymphoma Using the Dual PI3K $\delta / \gamma$ Inhibitor RP6530. Clin. Cancer Res. 2019, 25, 1098-1112. [CrossRef]

151. Lobera, M.; Madauss, K.P.; Pohlhaus, D.T.; Wright, Q.G.; Trocha, M.; Schmidt, D.R.; Baloglu, E.; Trump, R.P.; Head, M.S.; Hofmann, G.A.; et al. Selective class IIa histone deacetylase inhibition via a nonchelating zinc-binding group. Nat. Chem. Biol. 2013, 9, 319-325. [CrossRef]

152. Guerriero, J.L.; Sotayo, A.; Ponichtera, H.E.; Castrillon, J.A.; Pourzia, A.L.; Schad, S.; Johnson, S.F.; Carrasco, R.D.; Lazo, S.; Bronson, R.T.; et al. Class IIa HDAC inhibition reduces breast tumours and metastases through anti-tumour macrophages. Nature 2017, 543, 428-432. [CrossRef] [PubMed]

153. Ruffell, B.; Chang-Strachan, D.; Chan, V.; Rosenbusch, A.; Ho, C.M.T.; Pryer, N.; Daniel, D.; Hwang, E.S.; Rugo, H.S.; Coussens, L.M. Macrophage IL-10 blocks CD8+ T cell-dependent responses to chemotherapy by suppressing IL-12 expression in intratumoral dendritic cells. Cancer Cell 2014, 26, 623-637. [CrossRef] [PubMed]

154. Yan, D.; Kowal, J.; Akkari, L.; Schuhmacher, A.J.; Huse, J.T.; West, B.L.; Joyce, J.A. Inhibition of colony stimulating factor-1 receptor abrogates microenvironment-mediated therapeutic resistance in gliomas. Oncogene 2017, 36, 6049-6058. [CrossRef] [PubMed]

(C) 2019 by the authors. Licensee MDPI, Basel, Switzerland. This article is an open access article distributed under the terms and conditions of the Creative Commons Attribution (CC BY) license (http://creativecommons.org/licenses/by/4.0/). 